Florida International University

FIU Digital Commons

$4-1-2010$

\title{
Comparison of Cardiovascular Disease Risk Factors between Single and Partnered Mothers: Data from the 2006 Health Survey of Adults and Children in Bermuda
}

Courtney Dill

Florida International University, cdill001@fiu.edu

DOI: $10.25148 /$ etd.FI10041630

Follow this and additional works at: https://digitalcommons.fiu.edu/etd

\section{Recommended Citation}

Dill, Courtney, "Comparison of Cardiovascular Disease Risk Factors between Single and Partnered Mothers: Data from the 2006 Health Survey of Adults and Children in Bermuda" (2010). FIU Electronic Theses and Dissertations. 158.

https://digitalcommons.fiu.edu/etd/158 


\title{
FLORIDA INTERNATIONAL UNIVERSITY
}

Miami, Florida

\section{COMPARISON OF CARDIOVASCULAR DISEASE RISK FACTORS BETWEEN \\ SINGLE AND PARTNERED MOTHERS: DATA FROM THE 2006 HEALTH \\ SURVEY OF ADULTS AND CHILDREN IN BERMUDA}

\author{
A thesis submitted in partial fulfillment of the \\ requirements for the degree of \\ MASTER OF SCIENCE \\ in \\ DIETETICS AND NUTRITION \\ by \\ Courtney Andréa Dill
}

2010 
To: Dean Fernando M. Treviño

R. Stempel College of Public Health and Social Work

This thesis, written by Courtney Andréa Dill, and entitled Comparison of Cardiovascular Disease Risk Factors between Single and Partnered Mothers: Data from the 2006 Health Survey of Adults and Children in Bermuda, having been approved in respect to style and intellectual content, is referred to you for judgment.

We have read this thesis and recommend that it be approved.

$\begin{array}{r}\hline \text { Victoria Castellanos } \\ \hline \text { Marcia Magnus } \\ \hline \text { Evelyn Enrione, Major Professor }\end{array}$

Date of Defense: April 1, 2010

The thesis of Courtney Andréa Dill is approved.

Dean Fernando M. Treviño R. Stempel College of Public Health and Social Work

Interim Dean Kevin O'Shea University Graduate School

Florida International University, 2010 


\section{DEDICATION}

I would like to dedicate this work to everyone who has supported me throughout its completion. To my mother and father, I appreciate your love and understanding; thank you for being you. 


\section{ACKNOWLEDGMENTS}

I would like to acknowledge the Department of Health, Government of Bermuda for providing me with the opportunity to utilize their data and produce meaningful work for my country. I would like to thank my committee members, Dr. Victoria Castellanos and Dr. Marcia Magnus, for their continued support throughout this process. My major professor, Dr. Evelyn Enrione, has been an integral part of developing this work. I appreciate her support, patience, and guidance throughout the entire process. 
ABSTRACT OF THE THESIS

COMPARISON OF CARDIOVASCULAR DISEASE RISK FACTORS BETWEEN

SINGLE AND PARTNERED MOTHERS: DATA FROM THE 2006 HEALTH

SURVEY OF ADULTS AND CHILDREN IN BERMUDA

by

Courtney Andréa Dill

Florida International University, 2010

Miami, Florida

Professor Evelyn Enrione, Major Professor

Women are a high-risk population for cardiovascular diseases (CVD); however relationships between CVD and subpopulations of mothers are sparse. A secondary data analysis of the 2006 Health Survey of Adults and Children in Bermuda was conducted to compare the prevalence of CVD risk factors in single $(n=77)$ and partnered $(n=241)$ mothers. A higher percentage of single mothers were Black $(\mathrm{p}<0.001)$, less educated $(p=0.002)$, and earned less income $(p<0.001)$ than partnered mothers. The majority of all mothers consumed fruits and vegetables below recommendations of the Bermuda Nutrition Services. Fast-food consumption $(p=0.068)$, moderate $(p=0.402)$ and vigorous $(p=0.117)$ physical activity did not differ significantly between the groups. However, significantly more single mothers omitted breakfast $(p=0.003)$, had a BMI $>25 \mathrm{~kg} / \mathrm{m}^{2}$ $(p=0.01)$ and reported high blood pressure $(p=0.004)$ and high cholesterol (0.017). Single mothers were nearly three times $(\mathrm{OR}=2.66)$ more likely to experience high blood pressure and two times $(\mathrm{OR}=2.22)$ more likely to have high cholesterol. Single mothers may benefit from nutrition education programs related to lowering CVD risk. 


\section{TABLE OF CONTENTS}

CHAPTER

PAGE

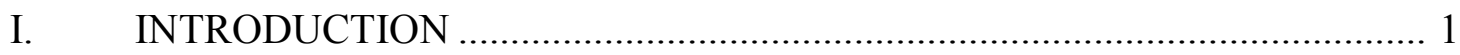

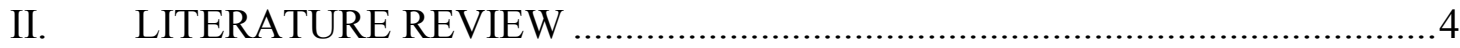

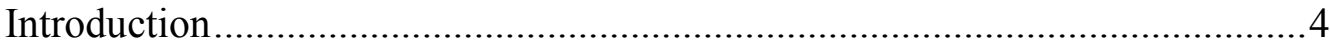

Mothers and their Role in Society .............................................................4

Women and Cardiovascular Disease .........................................................5

Health and Partner Status in Mothers ..........................................................6

Cardiovascular Disease Risk Factors and Partner Status in Mothers ............... 10

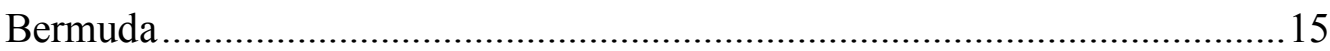

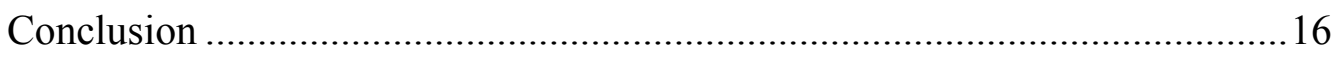

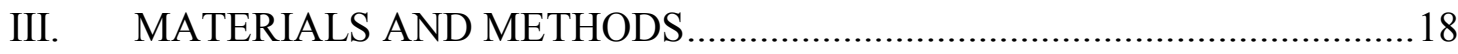

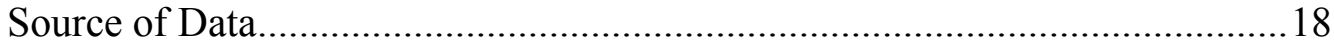

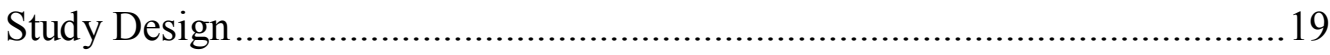

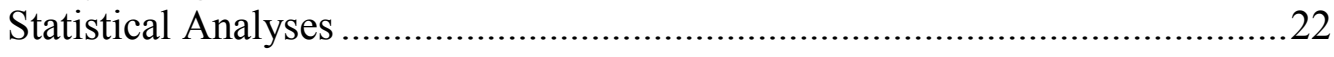

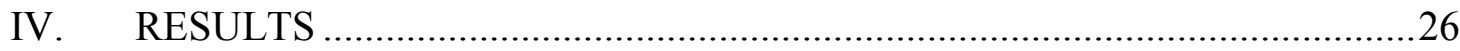

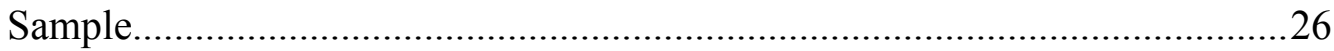

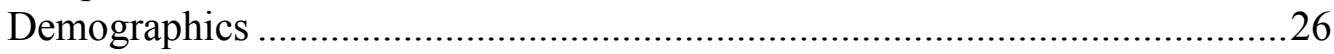

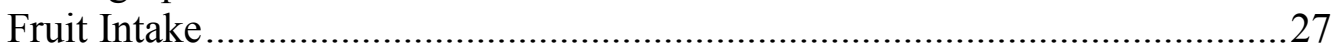

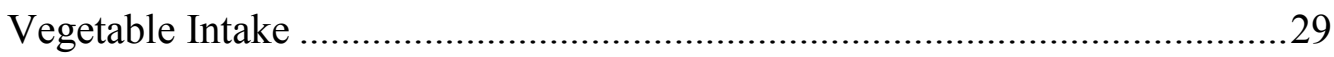

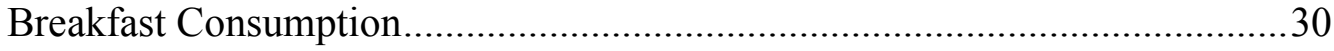

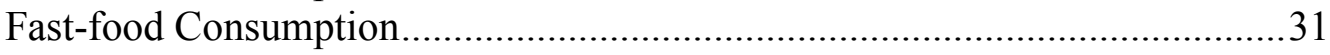

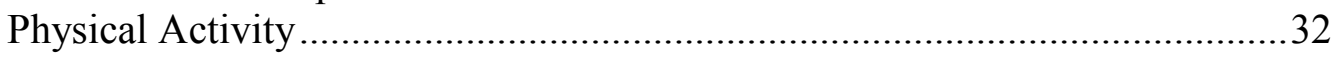

High blood pressure, High cholesterol, and Overweight/Obese......................33

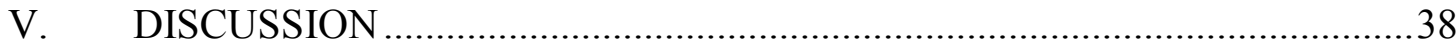

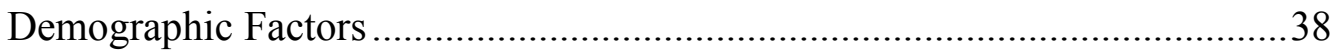

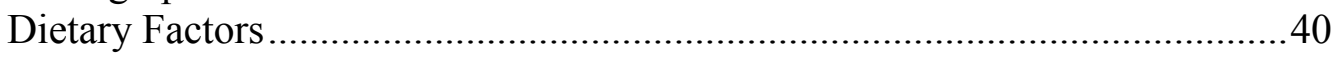

Physical Activity ................................................................................... 43

High blood pressure, High cholesterol, and Overweight/Obese.....................44

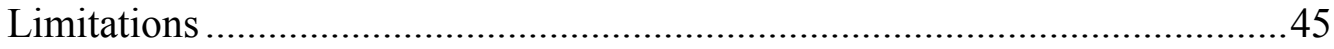

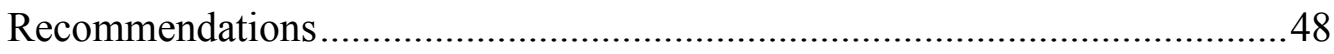

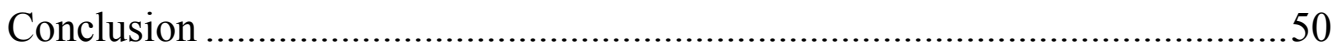

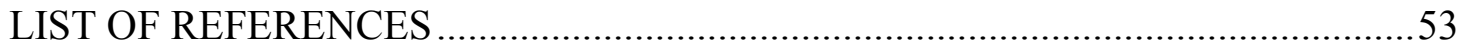




\section{LIST OF TABLES}

TABLE

PAGE

1. Demographics of single and partnered mothers based on the 2006 National Health Survey of Adults and Children in Bermuda.

2. Moderate physical activity of single and partnered mothers from the 2006 National Health Survey of Adults and Children in Bermuda

3. Vigorous physical activity of single and partnered mothers from the 2006

National Health Survey of Adults and Children in Bermuda 35

4. High blood pressure and high cholesterol awareness in single and partnered mothers based on the 2006 National Health Survey of Adults and Children in Bermuda

5. Body mass index (BMI) of single and partnered mothers calculated from self-reported height and weight of the 2006 National Health Survey of Adults and Children in Bermuda. 


\section{LIST OF FIGURES}

FIGURE

PAGE

1. Distribution of single and partnered mothers based on the 2006 National Health Survey of Adults and Children in Bermuda.

2. Fruit intake of single and partnered mothers based on the 2006 National Health Survey of Adults and Children in Bermuda

3. Vegetable intake of single and partnered mothers based on the 2006 National Health Survey of Adults and Children in Bermuda.....

4. Breakfast consumption of single and partnered mothers based on the 2006 National Health Survey of Adults and Children in Bermuda

5. Fast-food consumption of single and partnered mothers based on the 2006 National Health Survey of Adults and Children in Bermuda 


\section{CHAPTER I}

\section{INTRODUCTION}

Cardiovascular diseases (CVD) are debilitating chronic diseases causing approximately 16.5 million deaths annually and globally (1). While CVD have been addressed in various racial and ethnic populations, CVD prevalence and risk factors have also been extensively examined in women (2-12). According to the 2009 Women and Health publication presented by the World Health Organization, CVD are the leading causes of death for women worldwide (1). While women have been identified as a highrisk population for CVD incidence, research establishing relationships between CVD and the role of parenting in women is sparse $(13,14)$.

Parents are important components of the family unit and household (18). In addition, single and two-parent households are defining family structures that impact the intrinsic health, social, and economic status of the parents and the family $(13,14,19,20)$. The effect that single and two-parent households have on the family unit differs between each group. Over 100 years ago, researchers established a correlation between marital status, parenthood and health status concluding that single parents have worse health than partnered parents (21). Studies suggest that single mothers are a high-risk population group that experiences lower physical and mental health status, particularly in the United States, Canada, Great Britain, and Sweden (13, 14, 22-24). Single mothers are associated with more CVD risk factors (high blood pressure, low socioeconomic status, and low education level) when compared to partnered mothers in both the United States and Canada $(13,14)$. 
It is important to understand the association between CVD risk factors and motherhood because of the vital role mothers have in the family, society, and development of children (15-17). Mothers have an impact on the social interactions and overall health of their children (15-17). Thus, mothers have been found to help mold their children, and the physical and emotional support that a mother provides for her family is invaluable (15). Mothers' health ultimately impacts the family's health and consequently it is imperative that a mother's health is further examined. Researchers in the U.S. and Canada have demonstrated that single mothers are a potential high-risk population for CVD; however it is unclear if a similar trend occurs in other countries, specifically Bermuda.

Single parent families are an important construct of households in Bermuda. According to the Bermuda Population and Housing Census (2000), 66\% of all households consist of family units while the remaining $34 \%$ of households represents one person households or households of unrelated persons (25). Thus the majority of household units in Bermuda are affected directly by the social, economic and health impacts of family dynamics. Of these family households, $25 \%$ are partnered parent units while $11 \%$ are single parent families (25). As CVD cause the greatest mortality in Bermuda, CVD are the leading causes of death for women worldwide, and single mothers are associated with more CVD risk factors than partnered mothers, it is important to examine the relationship between partner status of women and CVD risk factors $(1,13$, $14,25)$.

Therefore, the purpose of this study is to investigate CVD risk factors of single and partnered mothers from the data of the 2006 National Health Survey of Adults and 
Children in Bermuda. The objective of this secondary data analysis is to compare CVD risk factors of single mothers to partnered mothers living in Bermuda. As studies have identified single mothers at increased risk for developing CVD, it is hypothesized that in Bermuda, being a single mother is associated with more CVD risk factors than being a partnered mother $(13,14)$. 


\section{CHAPTER II}

\section{LITERATURE REVIEW}

\section{INTRODUCTION}

Cardiovascular diseases (heart attacks, stroke, and angina) are the primary cause of death of women worldwide (1). Numerous studies address correlations between women and CVD; however studies are relatively sparse in subpopulations of mothers (214). Mothers are an influential demographic of women as they have an impact on the health, socialization, and behaviors of their children and families (15-17). Family households not only impact the entire family, but single and two-parent households ultimately have an effect on the health and financial status of the parents. In particular, single mothers have worse self-perceived health status when compared to partnered mothers (22-24). Upon further examination of health status, single mothers are associated with more CVD risk factors when compared to partnered mothers in the U.S. and Canada $(13,14)$. Furthermore, studies are not available that examine the CVD risk profile of mothers in Bermuda; a country where CVD are the leading causes of death and family households are an important construct of the island.

\section{MOTHERS AND THEIR ROLE IN SOCIETY}

Mothers are an important demographic of women in today's society (15).

Furthermore, they have great influence on the social development, health status, and financial status of their families and their children (15-17).

\section{WOMEN AS FOOD GATE-KEEPERS AND EFFECTS ON FAMILY}

Research suggests that women are an integral component of the family because of their evident impact on the social and health dynamics of the family unit (26-28). There 
exist various relationships between CVD risks and family dynamics. For example, documented correlations exist between family members and their diet and physical activity behaviors $(29,30)$. In particular, women and most often mothers have been noted as being food gatekeepers of the household with responsibilities involving meal preparation and shopping $(26,27)$. Thus women are extremely influential when considering the dietary habits of the family unit. This is an important concept as Wild et al., have suggested matriarchal models to serve as catalysts for CVD risk reduction and CVD prevention in families (26). As mothers have a substantial influence on the dietary habits of their families, which ultimately impacts their CVD risk profile, it is imperative that mothers are further examined as potential health role models for their children and their families.

\section{WOMEN AND CARDiovascular Disease}

Women have been identified as a high-risk population for developing CVD (7, 31). In the United States, 250,000 women die from coronary artery disease (CAD) each year (7). In addition, more women than men have succumbed to ischemic heart disease (IHD) since 1984 (7). Women also tend to be undertreated and under-diagnosed for CVD and its corresponding risk factors (31). Mosca and colleagues utilized a United States telephone survey, conducted in 1997, to obtain their study sample of women 25 years and older $(\mathrm{n}=914)$. Mosca et al., assessed heart disease perceptions of women by measuring: 1) knowledge of heart disease and stroke risks; 2) perceptions of heart disease; and 3) knowledge of symptoms and preventive measures (7). The results revealed that $61 \%$ of women responded that cancer was the greatest health problem for women and only $8 \%$ reported that heart disease or stroke was their greatest health 
concern (7). In addition, $51 \%$ of women reported they were moderately well informed about heart disease (7). Thus, in spite of CVD being a major public health issue and the leading cause of death for women, they may not perceive this chronic disease to be a problem.

\section{Health And Partner Status in Mothers}

There has been evidence suggesting a relationship between health, partner status, and motherhood; however this has only been identified in limited populations $(13,14,22-$ 24). Mothers are an important construct of society as they have an effect on the health and development of their children (15-17). Thus, the health and well-being of mothers is significant as they have a vital role in the development of their children and ultimately society.

Reeves and colleagues administered a postal questionnaire to 21,603 adults aged 16-70 years in the Trent Region of Great Britain (22). The questionnaire was comprised of closed-ended questions including: sociodemographic information, health-related behavior, self-perceived health status, stressors, social networks and perceptions of how health could be improved. Lone mothers were female respondents with at least one child aged $\leq 16$ years of age with no other adults living in the household. Partnered mothers were those women who responded living with a partner. The analytic sample (after excluding males and those women who did not meet the inclusion criteria) included 2085 mothers; $n=188(9 \%)$ lone mothers and $n=1897$ (91\%) partnered mothers. Reeves et al., revealed that more lone mothers smoked $(p<0.0001)$, were underweight with a BMI $<20$ $\mathrm{kg} / \mathrm{m}^{2}(\mathrm{p}=0.0005)$; and were less likely to perceive their health status as good $(\mathrm{p}=0.0016)$. Additionally, single mothers perceived that having less stress would ultimately improve 
their health (22). Although the study did not investigate the dietary habits, chronic disease risk factors, and chronic disease incidence of mothers, it did find that lone mothers have lower perceived health status when compared to partnered mothers (22).

Researchers in Sweden identified lone mothers as having lower health status (selfperceived health status and long-term illnesses affecting work or movement) when compared to partnered mothers (23). Burstrom and colleagues conducted a secondary data analysis using the annual Survey of Living Conditions (ULF). The ULF, which has been carried out annually since 1975, conducted face-to-face interviews using a random sample of Swedish individuals aged 16 years and older (23). This particular study investigated trends in the health and socioeconomic conditions of lone mothers in Sweden (23). Consequently, Burstrom et al., compared the demographic, socioeconomic and health status of lone and coupled mothers over 17 years old. The analytic sample included 19,711 mothers: $\mathrm{n}=2,776$ lone mothers and $\mathrm{n}=16,935$ coupled mothers. Lone mothers were defined as not currently living with a partner and living with their children aged $\leq 18$ years. Conversely, coupled mothers were defined as currently cohabiting with a partner and living with her children aged 18 years or less. The study revealed an increase in single mothers (13.4\% to $16.0 \%$ ) from the early 1980 s to the 1990 s. The prevalence of poverty (income less than 50\% of median income) was higher in lone mothers; however poverty rates increased over time in both lone and coupled mothers (23). Lone mothers had worse health (self-perceived and illnesses affecting work and movement) than coupled mothers throughout the entire study. Additionally, both lone $(p=0.0004)$ and coupled $(p=0.004)$ mothers self-reported their health as less than good. Furthermore, the prevalence of less than good health increased in the youngest group of 
lone mothers (16-24 years) from $24.2 \%$ in $1988-1991$ to $40.5 \%$ in $1992-1995$. Burstrom et al., attributed this finding to increased strain on mothers of young children; financial burdens which are more evident in younger adults, especially in lone mothers; and conflicts between parenting and working. The results reveal a population of lone mothers with low self-perceived health status (23).

Higgins and colleagues used a qualitative approach to explore heart health risk factors and perspectives in a group of low-income lone mothers (24). This Canadian study included a sample of 38 lone mothers (17-53 years) who were living on social assistance. Thirty-six mothers participated in one of seven focus groups, and personal interviews were conducted with two lone mothers. The purpose of the focus groups and interviews was to understand: participants' knowledge of heart health and risk factors, factors in their lives that might contribute to CVD risk, factors in their lives that may prevent healthy heart behaviors, and their perceptions of social policy relating to healthy heart behaviors (24). Participants reported that their life circumstances (financial, social support) influenced their ability to adopt heart-healthy lifestyles. For example, mothers stated that lack of money limited their ability to buy fruits and vegetables. This statement reveals a perceived belief that eating healthy is expensive. In addition, the mothers reported regularly sacrificing fruits and vegetables for themselves in order to provide for their children.

\section{$\underline{\text { LIMITATIONS }}$}

While studies reveal lone mothers to be a demographic of women with lower selfperceived health status and evident financial barriers, these studies have several limitations (22-24). Sample sizes may serve as a limitation; for example Higgins et al., 
utilized 38 lone mothers in their qualitative study. However other studies examining motherhood and health status were able to utilize a large sample $(n=19,711)$ and observed significant differences between the health status of lone and partnered mothers (23).

Also, self-reported data is always subject to bias. Body mass index (BMI) was utilized by Reeves to assess weight status of mothers but they utilized self-reported height and weight to calculate BMI in these mothers (24). Due to possible under- and over-reporting, researchers may not have been able to calculate accurate BMI values. Furthermore, BMI is not a measure of lean body mass or fat mass and thus cannot be used as the sole tool to identify individuals as under- or over-weight. Despite the limitations of utilizing BMI, it still provides an indication of the weight status in lone and partnered mothers.

The measurement of health status was also not consistent throughout the studies. For example, Reeves et al., measured self-perceived health status utilizing self-ratings (i.e. good, fairly good, not good) from the lone mothers based on the past 12 months. On the contrary, Burstrom and colleagues measured self perceived health status by examining lone mothers' responses (i.e. good, bad, something in between) in addition to any limiting illnesses that may affect work or daily activities. Researchers also examined financial barriers and social support to define a mother's health status (22-24). Despite examining different variables and inconsistencies among the literature, lone mothers consistently have lower perceived and actual health status when compared to partnered mothers (22-24). Thus by addressing cardiovascular and overall health in mothers, one will provide awareness to an important and socially influential demographic of women. 


\section{Cardiovascular Disease Risk Factors and Partner Status in Mothers}

With regards to the correlation between partner status and CVD risk in mothers, there exist only few published studies and these have been conducted in the United States and Canada $(13,14)$. Despite the differences in geography and culture, the consensus of these studies remains the same: single mothers experience higher rates of CVD in comparison to partnered mothers $(13,14)$.

Young and colleagues utilized the 1998-1999 National Population Health Survey (NPHS) of Canada to conduct a secondary data analysis (13). They wanted to determine whether being a single mother in Canada is associated with CVD risk factors. Lone mothers were defined as living without a cohabitating partner and with at least one child $\leq 18$ years. Conversely, partnered mothers were defined as living with a partner and at least one child $\leq 18$ years. A large sample size of mothers $(n=2,184)$ where $22 \%(n=478)$ were single mothers and $78 \%(n=1,706)$ were partnered mothers was utilized. The risk factors studied were: smoking status, physical inactivity, and body mass index (BMI). Physical activity was characterized by total energy expenditure of leisure activities. Body mass index for this particular study was divided into normal $\left(\leq 25 \mathrm{~kg} / \mathrm{m}^{2}\right)$ and overweight $\left(>25 \mathrm{~kg} / \mathrm{m}^{2}\right)$. Lone mothers were associated with lower income and education levels. Lone mothers $(23.3 \%)$ were also more likely to report having three or more chronic conditions than partnered mothers (14.5\%). With regards to BMI and physical inactivity, mothers did not differ significantly. Approximately $40 \%$ of mothers were overweight while $55 \%$ of lone mothers and $59 \%$ of partnered mothers were physically inactive. As a result, overweight and physical inactivity are potential 
significant contributors to the mothers' CVD risk profiles. Consequently, lone mothers in Canada are associated with more CVD risk factors when compared to partnered mothers. Young, in collaboration with other researchers, utilized the National Health and Nutrition Examination Survey III (NHANES III) results to conduct another secondary data analysis. Young et al., evaluated CVD risk (smoking, nongestational diabetes, Creactive protein, hypercholesterolemia, and high blood pressure) and lifestyle factors (physical activity and BMI) in partnered and lone mothers (14). Body mass index was categorized into normal $\left(<27.3 \mathrm{~kg} / \mathrm{m}^{2}\right)$, obese $\left(27.3-29.9 \mathrm{~kg} / \mathrm{m}^{2}\right)$, and very obese $(>30$ $\mathrm{kg} / \mathrm{m}^{2}$ ). A sample size of 1446 mothers between the ages of 18 and 60 years was enrolled, with lone mothers representing $43 \%(\mathrm{n}=623)$ and partnered mothers representing 57\% ( $\mathrm{n}=832)$. Young et al., defined mothers as women with one or more family members (children by blood or marriage, or adopted, foster, or godchildren) under the age of 17 years who lived in their household (14). Lone mothers included women who were widowed, divorced, separated, never married, or married without the spouse living in the household. Partnered mothers included those who reported being married. Exclusion criteria were: marital status unknown or missing, having no child under age 17, or if mothers were over age 60 years. The CVD risk factors were all determined through self-reported answers.

Young et al., identified lone mothers to be older, less educated, have lower income levels, and report their ethnicity as being predominantly non-Hispanic Black (14). Lone mothers were four times more likely to have used Medicaid and food stamps when compared to partnered mothers. In addition, lone mothers were twice as likely to report not having enough to eat in the past year. This study also revealed that lone mothers 
were approximately 3.5 times more likely to be very obese and 3.3 times more likely to have had a CVD event when compared to partnered mothers. Additionally, one third of all mothers, lone and partnered inclusive, had hypertension, hypercholesterolemia, diabetes, high C-reactive protein, or all of these risk factors when adjusted for age (14). Consistent with their previously mentioned study, Young and colleagues identified lone mothers to be a target group for CVD primary prevention (14).

While the aforementioned studies reveal lone mothers to be associated with more CVD risks, there exist evident strengths and limitations with the studies. The sample sizes of both studies were large thus strengthening the validity of the results. However, the definition of lone and partnered mothers is not consistent among the studies. This is probably due to the country-specific age of adulthood and the study's definition of motherhood. Consequently, future studies need to offer a country-specific definition of lone or partnered motherhood in addition to adulthood.

The cohorts of the NPHS study (22\% lone mothers and $78 \%$ partnered mothers) were not as evenly distributed when compared with the NHANES III study ( $43 \%$ lone mothers and $58 \%$ partnered mothers) however this is most likely due to the study design that relied heavily on the results and participants of the primary survey $(13,14)$. Despite the difference in sample distribution, it is evident in both the United States and Canada, that single mothers experience higher rates of chronic disease when compared to partnered mothers.

The World Health Organization has adopted various BMI categories to differentiate between underweight, normal weight, overweight, and obese (32); however the NPHS study did not address all BMI categories pertinent to CVD risk (i.e. obese $>30$ 
$\mathrm{kg} / \mathrm{m}^{2}$ ). In addition, the NHANES III secondary data analysis study utilized different BMI categories [normal $\left(<27.3 \mathrm{~kg} / \mathrm{m}^{2}\right)$, obese $\left(27.3-29.9 \mathrm{~kg} / \mathrm{m}^{2}\right)$, and very obese $(>30$ $\left.\mathrm{kg} / \mathrm{m}^{2}\right)$ ] which were possibly defined by the primary study (14). Despite evident limitations associated with utilizing BMI (inaccurate measure of body fatness), BMI and CVD risk are positively correlated (2). Thus knowing if mothers are in the highest risk category for BMI will aid in understanding their CVD risk profile and reducing their CVD risk.

The risk factors contributing to the high rates of CVD incidence in single mothers differed depending on the country. The NHANES III secondary data analysis identified lone mothers as being more likely to be obese (BMI: 27.3 - 29.9). Conversely, the study utilizing the NPHS Canadian data identified no significant difference between lone and partnered mothers with regards to obesity (14). These results may be different because Canada's obesity rates are slightly lower than the U.S. obesity rates $(23.1 \%$ and $34.3 \%$ respectively) $(33,34)$. When comparing the obesity rates by race and ethnicity in the U.S. and Canada, it is evident that non-Hispanic Blacks are more overweight and/or obese in these countries $(35,36)$. In the United States, Pan and colleagues identified $35.7 \%$ of non-Hispanic Blacks to have a $\mathrm{BMI} \geq 30.0 \mathrm{~kg} / \mathrm{m}^{2}$ when compared to $23.7 \%$ of non-Hispanic Whites as evidenced by the 2006-2008 Behavioral Risk Factor Surveillance System surveys. According to the 2004 Canadian Community Health Survey, $37.6 \%$ of Blacks were overweight (BMI $25-29.9 \mathrm{~kg} / \mathrm{m}^{2}$ ) when compared to $36.5 \%$ of Whites. Thus there exists an evident race/ethnic disparity in BMI which may be an underlying contributor to the BMI differences within these countries. 
Furthermore, the evident cultural and social differences between the two countries may impact obesity in mothers as it is a multi-factorial condition. Regarding physical activity, the NPHS sample of mothers did not differ significantly, however in the NHANES III sample lone mothers were more likely to be physically active (14). This result seems counterintuitive as lone mothers were more likely to be obese despite being more physically active when compared to partnered mothers. Physical activity may have differed between the two samples because of cultural and environmental differences evident in these two countries. The mothers' environment (use of car versus public transportation, availability of safe walking areas) can greatly impact daily physical activity. Consequently, Young and colleagues have revealed contradictory results between the U.S. and Canadian sample of mothers.

As only two studies have investigated single and partnered mothers and they show conflicting results, more studies are warranted, not only in these countries but in others to see if the there is a relationship between lone parenting and CVD risk factors. Bermuda has a similar culture to the U.S. and Canada, as they are all developed countries having evolved from British rule. In addition, the health status of adults in all three countries tends to follow similar trends. For example, in 2004, 59.2\% of adults in Canada were overweight or obese, in $200663 \%$ of adults in Bermuda were overweight or obese, and in $2005-200667 \%$ of adults in the U.S. were overweight or obese $(25,33,34)$. In addition, heart disease is the leading cause of death in all three of these countries $(25,37,38)$. Due to the health and cultural similarities between Bermuda, the U.S., and Canada, and the fact that conflicting results were found in the U.S. and Canada, studying CVD risk factors 
in mothers living in Bermuda would provide further comparisons between motherhood, partner status, and CVD risk.

\section{BERMUDA}

\section{HOUSEHOLDS AND SINGLE PARENT FAMILIES}

Single- parent families are an important construct of households in Bermuda. According to the Bermuda Population and Housing Census (2000), 66\% of households are family households (single-parent families, partnered parent families, adult couples, and extended families), $28 \%$ are one-person households, and $6 \%$ are households of unrelated persons (18). Of the family households, $25 \%$ are partnered parent households, $20 \%$ are adult couple, $11 \%$ are single parent, and $10 \%$ are extended family households (25). Even though married couples represent the majority of family households, single parent families represent a significant proportion of family households (25). Thus single parent families (11\% of family households), while less prevalent than partnered parent families (25\% of family households), are an evident structural component of the Bermudian demographic.

\section{CARDIOVASCUlar Disease}

In Bermuda, CVD is a major public health issue accounting for $36 \%$ of all deaths in 2005 (25). The adults of Bermuda are experiencing increased rates of CVD risk factors. The 1999 Adult Survey in Bermuda reported 5\% of respondents having high blood pressure and 2\% having high cholesterol (25). In comparison, the 2006 Health Survey of Adults revealed 25\% of adults self-reported having high blood pressure and 34\% self-reported experiencing high cholesterol (25). While CVD is a major public 
health issue, studies addressing the relationship between Bermudians and CVD are sparse.

Social risk factors differ between partnered and single parents in Bermuda. According to the 2000 Population and Housing Census in Bermuda, single male and female headed households earn on average BMD $\$ 1,334$ less than two parent households (25). In 2004, partnered parent households were earning an average of BMD $\$ 2,930$ per week while single parent families in Bermuda were earning an average of BMD\$1,596 per week (25).

Consequently, mothers living in Bermuda are an important demographic of this society. Cardiovascular diseases (CVD) are a major public health issue for people living in Bermuda (25). In addition, women have a high risk for developing these chronic diseases. Mothers are an important construct of society as they have a significant impact on their families, the development of their children and ultimately society (15-17). Studying the relationship between CVD risk factors, motherhood, and partner status in Bermuda will provide further comparisons in an under-studied population of women.

\section{CONCLUSION}

Cardiovascular diseases (CVD) are the major causes of death for women worldwide (1). In addition, women tend to be under-treated and under-diagnosed, possibly due to an evident lack of knowledge of CVD in certain populations (31). This debilitating disease has been studied in various racial and ethnic groups, however the relationship between CVD and the subpopulation of mothers has rarely been studied (13, 14). 
Mothers are an important subpopulation of women as they play a vital role in the development of their children and ultimately society as well as food gatekeepers for their families $(15-17,26,27)$. Mothers comprise various family units including single parent and partnered parent households. Single mothers have been identified as having lower self-perceived health status when compared to partnered mothers (22-24). Single mothers have also reported sacrificing consumption of fruits and vegetables due to price, thus presenting a financial barrier for these women (24). Thus there appears to be a correlation between partner status of mothers and health status.

Regarding cardiovascular health, mothers have rarely been addressed in the literature. Only two studies, conducted in the U.S. and Canada, have addressed CVD and mothers $(13,14)$. These studies identified single mothers to be associated with more CVD risk factors (lower income, high blood pressure, high cholesterol, and obesity) when compared to partnered mothers. The findings of higher risk factors were the same despite some significant differences between the studies. Obesity rates and physical activity were not different in single mothers between the two studies. Due to the health and cultural similarities between Bermuda, the U.S., and Canada and the fact that conflicting results were found in the U.S. and Canada, studying CVD risk factors in mothers living in Bermuda would provide further comparisons between motherhood, partner status, and CVD risk. 


\section{CHAPTER III}

\section{MATERIALS AND METHODS}

\section{SOURCE OF DATA}

The Government of Bermuda, in conjunction with the Bermudian Ministry of Health, conducted the 2006 Health Survey of Adults and Children. The adult survey utilized the Behavior Risk Factor Surveillance System (BRFSS) with the 2005 survey questions, developed by Centers for Disease Control and Prevention of the United States of America (39). The 2005 BRFSS is a 20 Section, 26 Module continuous telephone health survey system designed to collect information on health risk behaviors, preventive health practices, and health care access primarily related to chronic disease and injury of people living in the 50 United States, District of Columbia, Puerto Rico, Guam, and US Virgin Islands (39). The system has been in effect since 1984 (39).

Nelson and colleagues conducted a review of the studies examining the reliability and validity of the BRFSS measures and they concluded that the BRFSS was highly reliable and valid for demographics, blood pressure screening, height, weight, and BMI (41). Additionally, the BRFSS was moderately reliable and valid for physical activity and fruit and vegetable consumption. The BRFSS has also been identified as a reliable measure of on-going health status in various populations $(40,41)$. The BRFSS was modified (age, race, education, income) for the 2006 National Health Survey of Adults and Children in Bermuda to be representative of the Bermudian population (42). In addition, certain questions (gun control) were omitted due to their irrelevance to the Bermudian population (42). 
To implement the BRFSS in Bermuda, a random sample of the noninstitutionalized, civilian Bermudian population was selected using random digit dialing where all prefixes for the land line telephones were listed and the remaining four digits were randomly generated. The prefixes for land lines cover the entire island, thus ensuring a representative sample of the Bermudian population. The random digit dialing system allowed for inclusion of listed and unlisted telephone numbers. As approximately $2 \%$ of households are without landlines in Bermuda, this further ensured a representative sample. Telephone interviews were conducted with 1650 households, which represented approximately $6 \%$ of the 28,000 household units in Bermuda. Research Innovations Inc. (Edmonton, Alberta Canada) collected, coded and analyzed the data between 30 January and 15 March 2006. The adult respondents included 587 men and 1,061 women. The primary results of the survey are published elsewhere (42).

\section{STUDY DESIGN}

A secondary data analysis of the 2006 Health Survey of Adults and Children in Bermuda was conducted to compare the prevalence of risk factors of cardiovascular diseases (CVD) in single and partnered mothers in Bermuda. The Department of Health, Government of Bermuda released the data stripped of identifiers. The Institutional Review Board of Florida International University, Miami, Florida (Approval Number: 031009-01) and the Bermuda Hospitals Board Ethics Committee, Hamilton, Bermuda approved the study.

$\underline{\text { SAMPLE }}$

Mothers were defined as females over the age of 18 years with at least one family member under the age of 17 years old living in the same household. Mothers were at 
least 18 years old as this is the legal age of adulthood in Bermuda (43). Single mothers self-reported residing in a single parent household and partnered mothers self-reported residing in a household of either two parents with children from the same union or two parents with children from different unions. Women who did not self-report their household status or did not have a child under the age of 17 years residing in the same household were excluded.

\section{CVD RISK FACTORS}

Questions related to demographics, diet, weight, physical activity, high blood pressure, and high cholesterol were reviewed. The variables and CVD risk factors, determined from the survey questions, included: age, race, education, annual household income, servings of fruits consumed (not including juice), servings of vegetables consumed, breakfast consumption, fast-food consumption, physical activity, high blood pressure, high cholesterol, and body mass index (BMI).

Women self-reported their age. Questions for race, education, and income were multiple-choice. Race options were Black, White, Asian, Black \& White, Black \& other, White \& other, or other specified ethnicity. The selections for education included never attended school or only attended kindergarten, primary/middle school, secondary/grammar school, technical/vocational pre-university, undergraduate university degree, graduate university degree, or professional qualification. Annual household income was determined from the following responses under $\$ 25,000, \$ 25,001$ to $\$ 50,000$, $\$ 50,001$ to $\$ 75,000, \$ 75,001$ to $\$ 100,000, \$ 100,001$ to $\$ 125,000, \$ 125,001$ to $\$ 150,000$, $\$ 150,001$ to $\$ 175,000, \$ 175,001$ to $\$ 200,000$ and over $\$ 201,000$. 
The same question format determined fruit and vegetable intake along with fastfood consumption and breakfast consumption. For fruits and vegetables, respondents were asked how many servings they usually ate by quantifying per day, per week, per month, per year, or by responding never, don't know/not sure, or refused. To assist them with quantification, respondents were informed that a serving of fruit was a "portion of fruit at breakfast" and "a serving of vegetables at both lunch and dinner would be two servings" (42). For fast-food meal consumption, interviewers explained that "fast food meals included hamburgers, fried chicken, hot dogs, French-fries, milk shakes, and soda" and then participants replied to the same format as fruits and vegetables to determine frequency (42). Mothers responded how often they consumed breakfast by indicating a number per week, per month, per year or by responding never, don't know/not sure, or refused.

Mothers were questioned about their moderate and vigorous physical activity. For both moderate and vigorous activity, mothers reported the number of days per week they perform each level of physical activity for at least ten minutes at a time. Mothers had the choice to report how many days per week they engaged in certain activities, if they do any moderate/vigorous physical activity for at least 10 minutes at a time, if they didn’t know/not sure, or refused. To assist with quantification, respondents were informed that "moderate activities cause small increases in breathing or heart rate, such as brisk walking, bicycling, vacuuming, or gardening”. Vigorous activities were explained as causing "large increases in breathing or heart rate, such as running, aerobics or heavy yard work". 
Respondents reported blood pressure and cholesterol awareness. Mothers were asked if they had ever been told by a doctor, nurse, or other health professional that they had either high blood pressure or high blood cholesterol. The choices were yes, no, don't know/not sure, or they could refuse. Based on self-reported body height and weight, body mass index (BMI) was calculated. Classifications of BMI were normal weight

(BMI: $18.5-24.9 \mathrm{~kg} / \mathrm{m}^{2}$ ), overweight (BMI: $25-29.9 \mathrm{~kg} / \mathrm{m}^{2}$ ), and obese (BMI: $30 \mathrm{~kg} / \mathrm{m}^{2}$ and above) based on the World Health Organization Body Mass Index (BMI) classifications (32).

\section{Statistical ANALYSES}

The responses from the primary survey were combined for each risk factor to ensure validity of the Chi-square distribution test. Mothers' self-reported ages were reclassified into four age categories: 18-34, 35-44, 45-54, and 55 and over. Race was reclassified into Black, White, and Other (Asian, Black \& White, Black \& other, White \& other, other specified ethnicity). Education was separated into two categories: secondary or less, and post secondary or higher. Annual household income was divided into $\$ 50,000$ or less, $\$ 50,001$ to $\$ 100,000$ and $\$ 100,001$ and higher.

Fruit consumption was classified as: 3 times per month or less, 1-2 times per week, 3-6 times per week, 1-2 times per day, and 3 or more times per day. The classifications were established to ensure that fruit intake recommendations could be delineated for both single and partnered mothers. According to the Nutrition Services, Bermuda Government they recommend that adults consume 2-4 servings of fruits per day for a healthy lifestyle (44). As a result, those mothers who are consuming fruits either 1- 
2 times per day or 3 or more times per day are consuming adequate fruits to meet the aforementioned national recommendations.

Vegetable consumption was divided into five categories: 1-2 times per week, 3-6 times per week, 1-2 times per day, 3-4 times per day, and 4-5 times per day. Classifications for vegetable intake were combined to assure that national recommendations could be compared between single and partnered mothers. The Bermuda Government, Nutrition Services recommends adults consume 3-5 servings of vegetables per day for optimal health (44). Thus mothers who are consuming vegetables either 3-4 times per day or 4-5 times per day are consuming adequate vegetables to meet national recommendations.

The breakfast consumption responses of mothers were categorized into: never, 15 times per month, 1-2 times per week, 3-4 times per week, and 5-7 times per week. The classifications for breakfast consumption were established to depict regular breakfast consumption (daily intake) between single and partnered mothers. There exists no defined recommendations for breakfast consumption; however it is suggested that breakfast be consumed on a daily basis to prevent weight gain (45). Thus, consumption of breakfast 5-7 times per week is representative of minimal weight gain and lower CVD risk.

Fast-food consumption was categorized by consumption of these foods: less than once per month, 1-3 times per month, 1-2 times per week, 3-6 times per week, 1-2 times per day, and 3 or more times per day. The classifications were established to ensure that fast-food consumption recommendations could be delineated for single and partnered mothers. The Well Bermuda, National Health Promotion Strategy of 2006 aims to reduce 
the proportion of adults consuming fast-foods at least once per week below $62 \%$ (25). Consequently, fast-food consumption of 1-3 times per month or less is associated with lower CVD risk.

Moderate and vigorous activities were divided into three categories. Mothers were classified into how many times per week they were engaging in at least 30 minutes of either moderate or vigorous activities which included: less than three, three to five, or six to seven. Classifications for both moderate and vigorous physical activity were combined to ensure that recommendations could be compared between single and partnered mothers. The Bermuda Heart Foundation, which recognizes the recommendations of the American Heart Association, advocates adults engage in moderate intensity physical activity on most (preferably all) days of the week $(46,47)$. In addition, the American Heart Association recommends engaging in vigorous physical activity three to five days per week $(46,47)$. As a result, those mothers engaging in moderate physical activity more than five times per week and vigorous physical activity at least three days per week are associated with lower CVD risk.

High blood pressure and high cholesterol were arranged into yes (which included having the condition, pre-hypertensive/pre-hypercholesterolemia, and border-line for both conditions) and no (which included not having the condition or having the condition only while pregnant). Body mass index (BMI) was classified into normal weight (BMI: 18-24.9 kg/m²), overweight (BMI: $25-29.9 \mathrm{~kg} / \mathrm{m}^{2}$ ), and obese (BMI: $>30 \mathrm{~kg} / \mathrm{m}^{2}$ ) as per the World Health Organization classifications (27).

The statistical analyses were computed using the SPSS Version 17.0.1 (SPSS Inc., Chicago Ill). Cross-tabulations were conducted for each variable and CVD risk factor of 
study. Percentages and frequencies were then calculated to describe the demographic, dietetic, and physiologic characteristics of the sample. The Chi-square test was performed to determine significant differences of CVD risk factors between single mothers and partnered mothers with significance set at $p<0.05$. To obtain the odds ratio (OR) for high blood pressure and high cholesterol, risk estimates were calculated. 


\section{CHAPTER IV}

\section{RESULTS}

\section{SAMPLE}

The analytic sample consisted of 318 mothers who met the inclusion criteria. As some mothers did not answer all of the questions, results are based on different sample sizes. The sample for annual household income was $n=71$ single mothers and $n=209$ partnered mothers. The sample of mothers who responded to the high blood pressure portion of the survey represented $n=77$ single mothers and $n=239$ partnered mothers. Mothers who responded to the high cholesterol section of the primary survey were $n=65$ single mothers and $n=204$ partnered mothers. The analytic sample for mothers who selfreported their height and weight so that BMI could be calculated were $n=73$ single mothers and $n=227$ partnered mothers.

\section{DEMOGRAPHICS}

Of the 318 mothers, the majority were partnered $(76 \%, n=241)$ (Figure 1). More single and partnered mothers were aged $35-44$ years $(n=29,37.6 \% ; n=114,47.3 \%$ respectively) (Table 1). The majority of single mothers chose Black as their race $(n=63$, $81.8 \%)$ whereas the majority of partnered mothers reported their race as White $(p<0.001)$ (Table 1). Single mothers had significantly less education when compared to partnered mothers $(p=0.002)$ (Table 1). Annual household income differed significantly $(p<0.001)$ between single and partnered mothers (Table 1). The majority of single mothers $(n=38$, $53.5 \%$ ) earned less than $\$ 100,001$ annually while the majority of partnered mothers $(\mathrm{n}=111,53.1 \%)$ earned more than $\$ 100,000$ annually. 
Figure 1. Distribution of single and partnered mothers based on the 2006 Health Survey of Adults and Children in Bermuda.

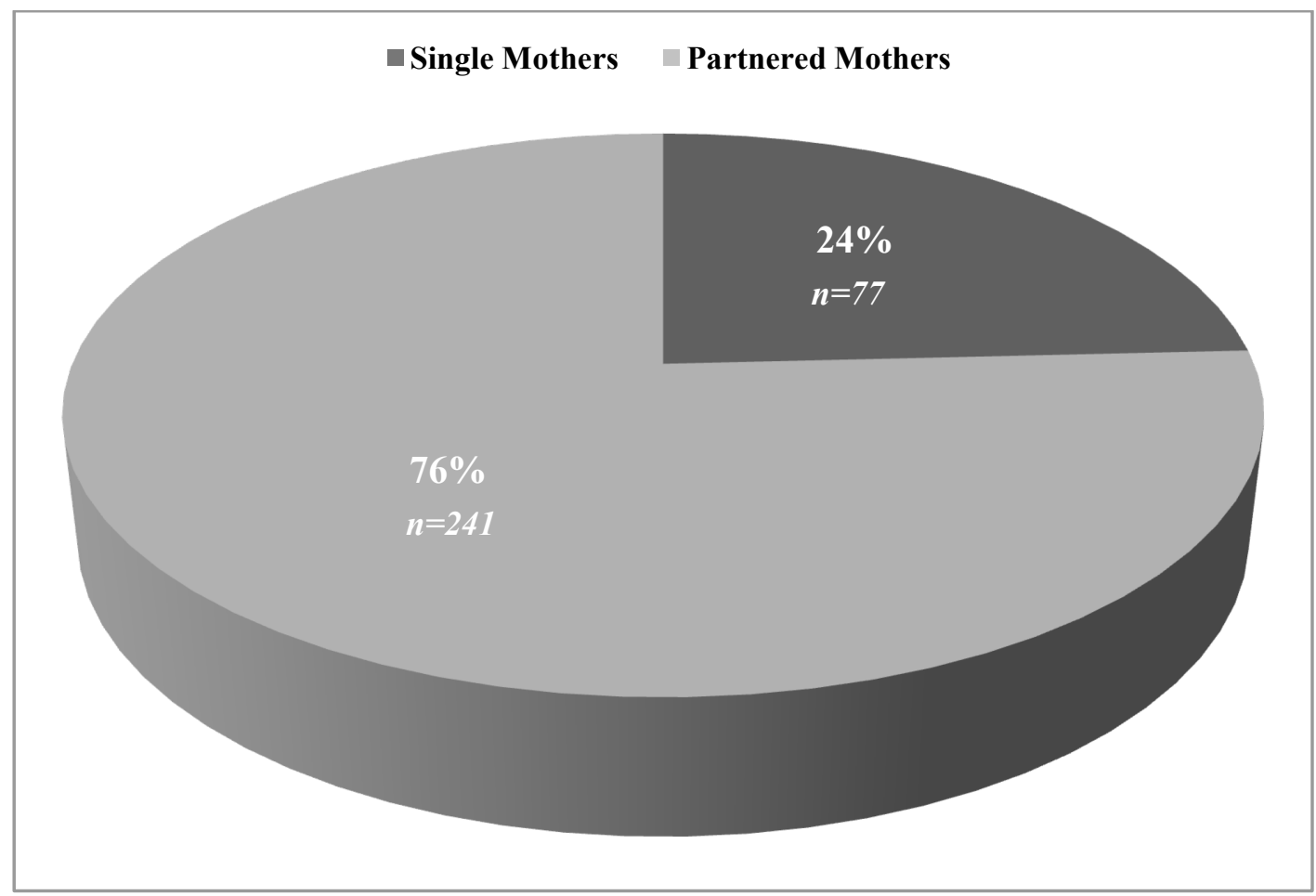

\section{FRUIT INTAKE}

A significant difference was not detected for fruit intake between single and partnered mothers $(\mathrm{p}=0.605)$. The majority of single $(\mathrm{n}=47,61.0 \%)$ and partnered $(\mathrm{n}=140,58.1 \%)$ mothers consumed one to two servings of fruits per day (Figure 2). Fruit was eaten three or more times per day by $22.4 \%(n=54)$ of partnered mothers, compared to $15.6 \%$ of single mothers $(n=12)$. 
Table 1. Demographics of single and partnered mothers based on the 2006 Health Survey of Adults and Children in Bermuda.

\begin{tabular}{|c|c|c|c|c|c|c|}
\hline & & \multicolumn{2}{|c|}{ SINGLE MOTHERS } & \multicolumn{2}{|c|}{ PARTNERED MOTHERS } & \multirow[t]{2}{*}{$P$} \\
\hline & & $\mathrm{N}=77$ & $\%$ & $\mathrm{~N}=241$ & $\%$ & \\
\hline \multirow{4}{*}{ Age (years) } & $18-34$ & 20 & 26.0 & 64 & 26.5 & \multirow{4}{*}{0.093} \\
\hline & $35-44$ & 29 & 37.6 & 114 & 47.3 & \\
\hline & $45-54$ & 22 & 28.6 & 57 & 23.7 & \\
\hline & $55+$ & 6 & 7.8 & 6 & 2.5 & \\
\hline \multirow{3}{*}{ Race } & Black & 63 & 81.8 & 89 & 36.9 & \multirow{3}{*}{0.001} \\
\hline & White & 13 & 16.9 & 126 & 52.3 & \\
\hline & Other $^{1}$ & 1 & 1.3 & 26 & 10.8 & \\
\hline \multirow{3}{*}{ Education } & Secondary or less & 31 & 40.3 & 49 & 20.3 & \multirow{2}{*}{0.002} \\
\hline & Post secondary or higher & 46 & 59.7 & 192 & 79.7 & \\
\hline & & $\mathrm{N}=71$ & $\%$ & $\mathrm{~N}=209$ & $\%$ & \\
\hline \multirow{3}{*}{ Annual Household Income } & $\$ 50,000$ or less & 25 & 35.2 & 15 & 7.2 & \multirow{3}{*}{0.001} \\
\hline & $\$ 50,001-\$ 100,000$ & 38 & 53.5 & 83 & 39.7 & \\
\hline & $\$ 100,001 \&$ over & 8 & 11.3 & 111 & 53.1 & \\
\hline
\end{tabular}

${ }^{1}$ Other: Asian, Black \& White, Black \& other, White \& other, other specified ethnicity 
Figure 2. Fruit intake of single and partnered mothers based on the 2006 Health Survey of Adults and Children in Bermuda.

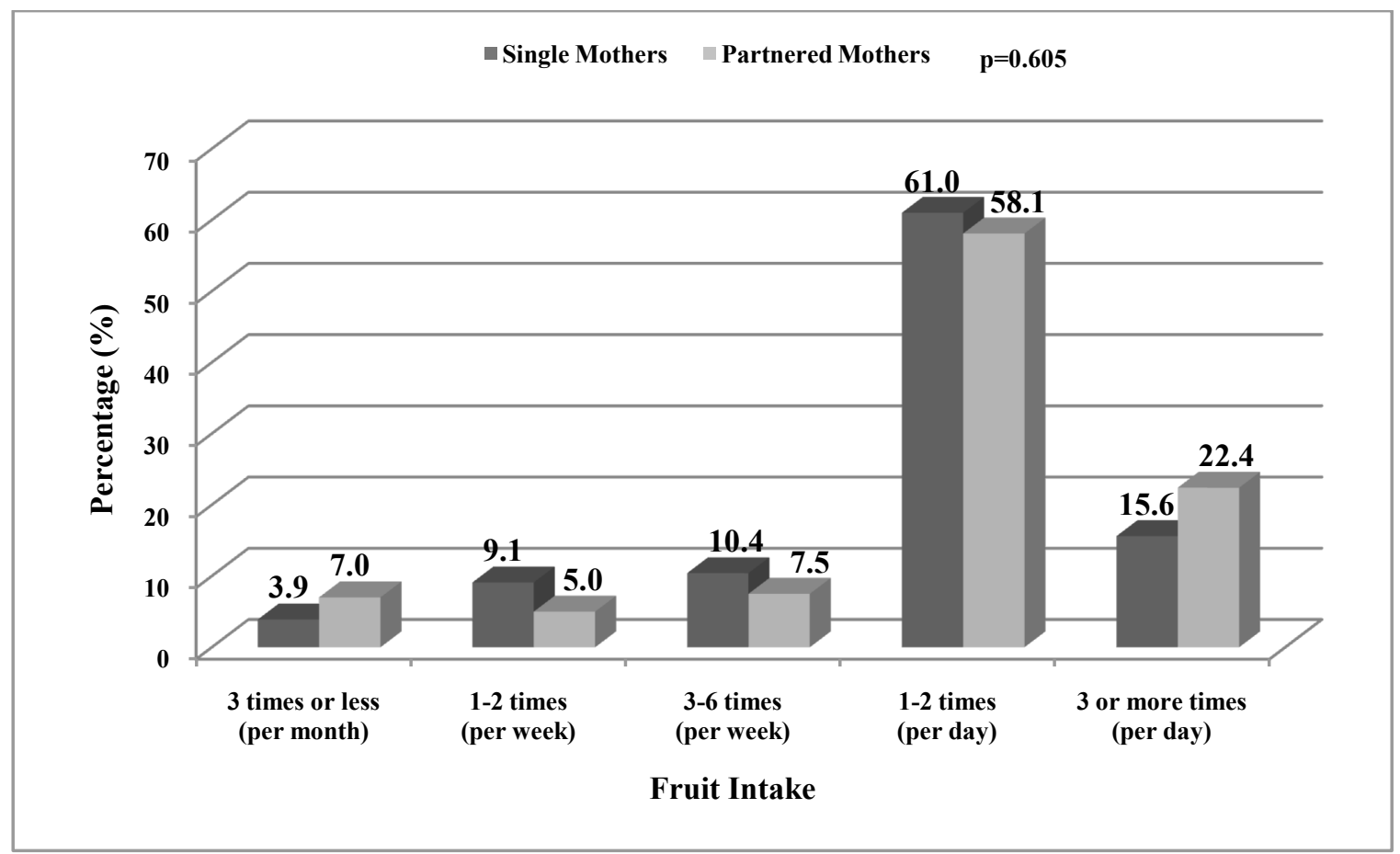

\section{VEGETABLE INTAKE}

The Chi-square revealed a different pattern of vegetable intake between single and partnered mothers $(p=0.025)$. Nearly three-fourths of the single mothers $(n=57$, $74.0 \%)$ and $71.8 \%(n=173)$ of the partnered mothers ate vegetables one to two times per day (Figure 3). More partnered mothers $(n=55,22.8 \%)$ than single mothers $(n=11$, $14.3 \%$ ) were consuming vegetables at least three times per day. Only one single mother $(1.3 \%)$ and one partnered mother $(0.4 \%)$ were consuming the minimal amount of vegetables (1-2 times per week). 
Figure 3. Vegetable intake of single and partnered mothers based on the 2006 Health Survey of Adults and Children in Bermuda.

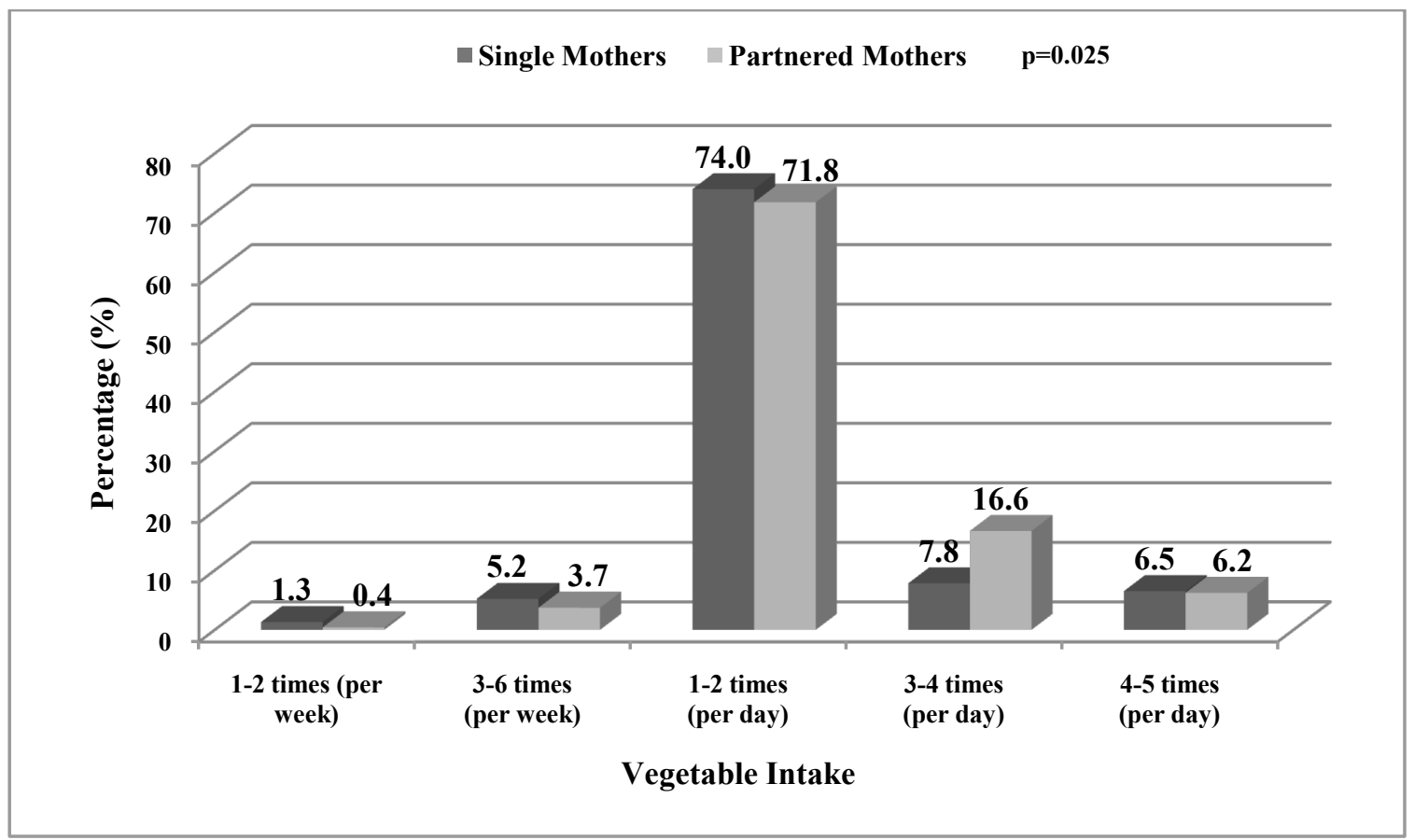

\section{BREAKFAST CONSUMPTION}

Breakfast intake was significantly different between single and partnered mothers $(\mathrm{p}=0.003)$. More partnered mothers $(\mathrm{n}=192,79.7 \%)$ consumed breakfast five to seven times per week than did single mothers $(n=53,68.8 \%)$ (Figure 4). Significantly more single mothers $(n=24,31.2 \%)$ consumed breakfast less than five times per week when compared to partnered mothers $(n=49,20.3 \%)$. The number of single mothers $(n=6$, $7.8 \%$ ) who consumed breakfast one to five times per month was higher than that of partnered mothers $(\mathrm{n}=3,1.2 \%)$. 
Figure 4. Breakfast consumption of single and partnered mothers based on the 2006 Health Survey of Adults and Children in Bermuda.

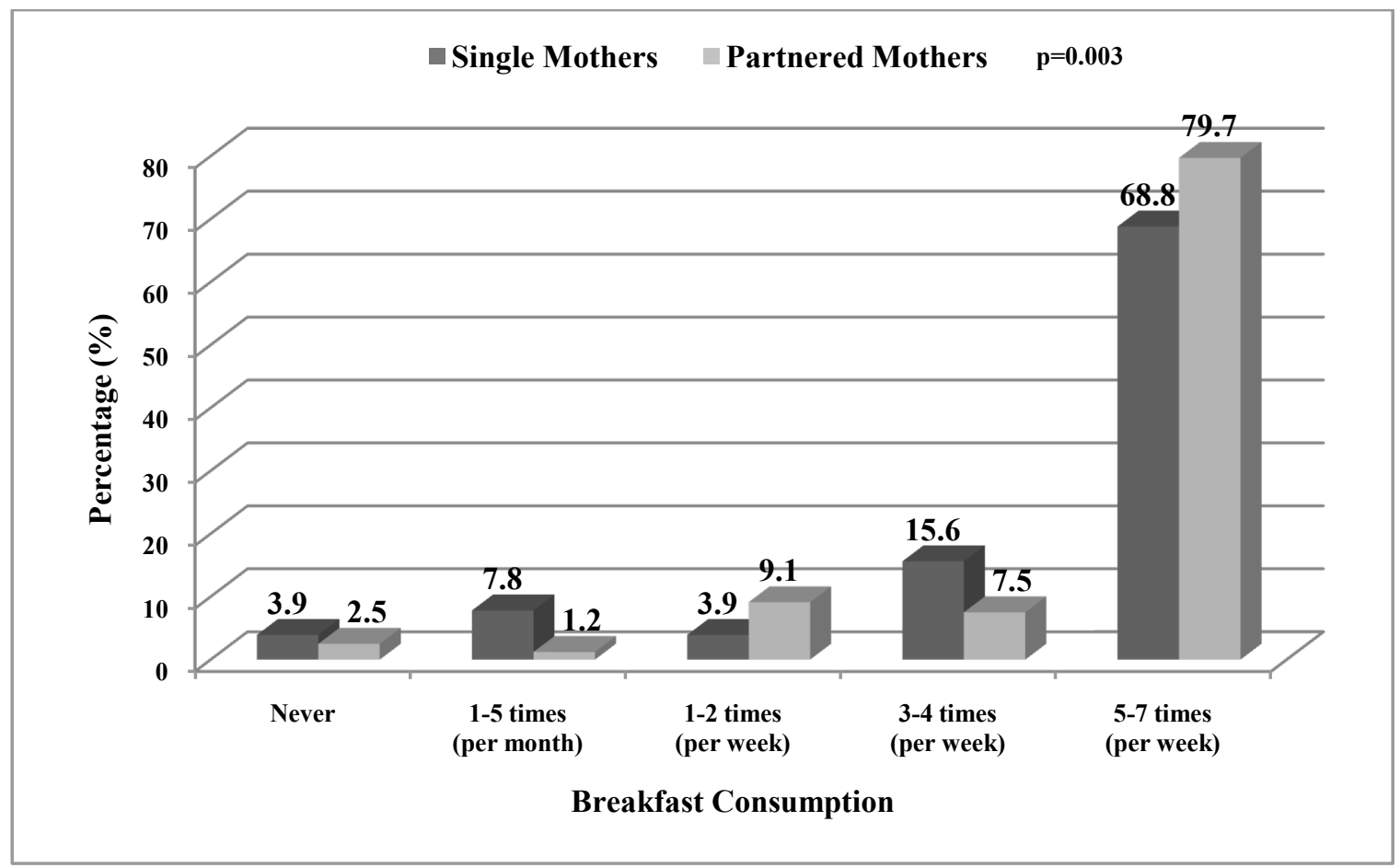

\section{FAST-FOOD CONSUMPTION}

Fast-food consumption was not significantly different $(p=0.065)$. A high percentage of single $(n=71,92.2 \%)$ and partnered $(n=231,95.9 \%)$ mothers consumed fast-foods less than once per day (Figure 5). Both single and partnered mothers consumed fast-food most often one to two times per week $(46.8 \%$ and $37.3 \%$ respectively) followed by one to three times per month (28.6\% and $29.9 \%$ respectively). The percentage of partnered mothers that reported consumption of fast-food less than once per month was $24.9 \%$ while the percentage of single mothers was $7.8 \%$. 
Figure 5. Fast-food consumption of single and partnered mothers based on the 2006 Health Survey of Adults and Children in Bermuda.

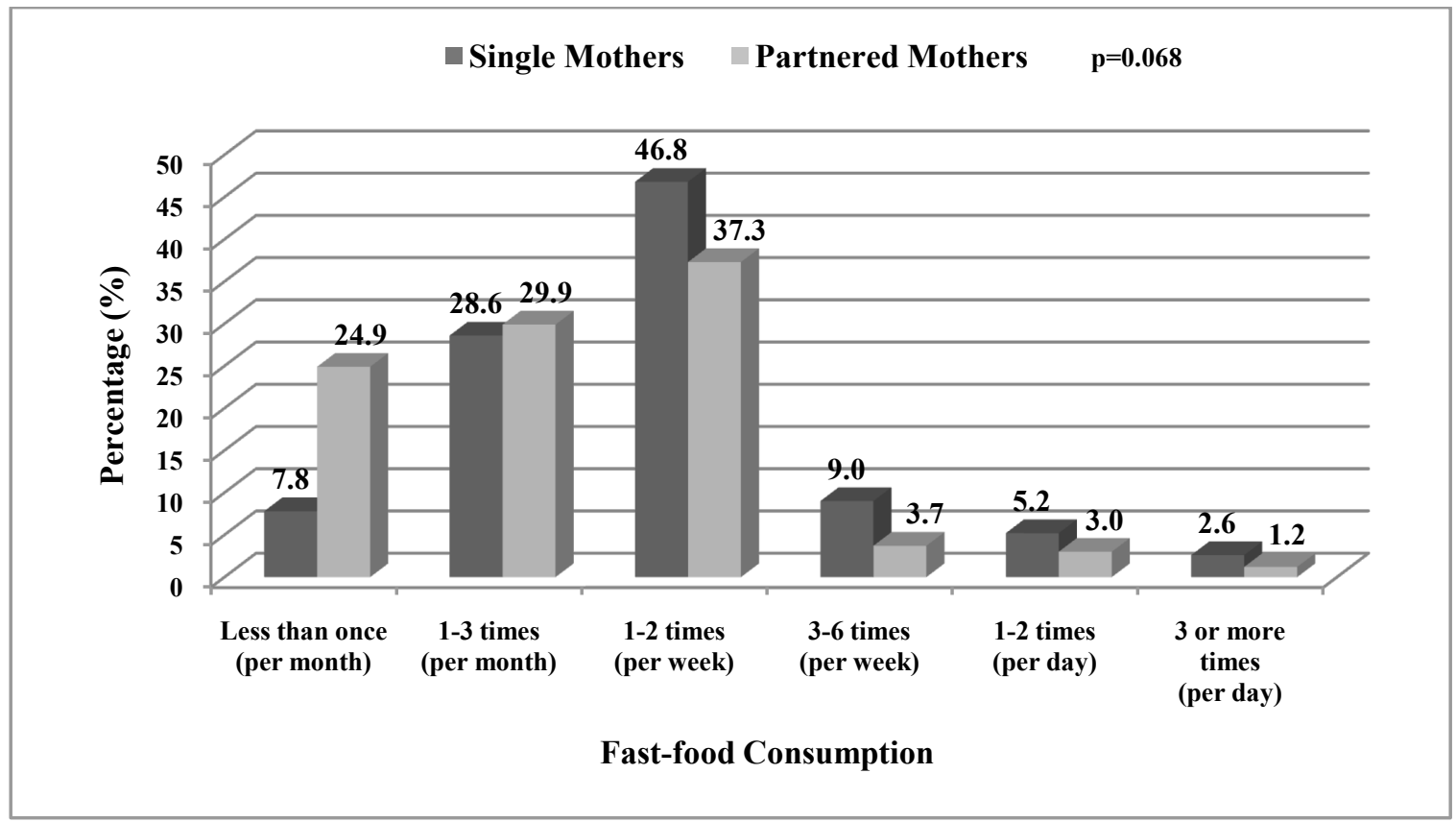

\section{Physical ACTIVITy}

No significant difference was identified for moderate or vigorous physical activity in single and partnered mothers $(\mathrm{p}=0.402$ and $\mathrm{p}=0.117$ respectively $)$. Over half of the single mothers $(n=42,54.5 \%)$ reported engaging in moderate physical activity three to five times per week whereas only a little over a third of the partnered mothers reported the same $(n=91,37.8 \%)$ (Table 2). Approximately, the same percentage of single mothers engaged in moderate physical activity six to seven times per week $(n=18,23.4 \%)$ and less than three times per week $(n=17,22.1 \%)$. The same was true for partnered mothers engaging in moderate physical activity six to seven times per week $(n=74$, $30.7 \%)$ and less than three times per week $(n=76,31.5 \%)$. The majority of single $(n=59$, $76.6 \%)$ and partnered $(n=165,68.5 \%)$ mothers reported they engaged in vigorous 
physical activity less than three times per week (Table 3). In addition, very few single $(n=4,5.2 \%)$ and partnered $(n=8,3.3 \%)$ mothers were engaging in vigorous physical activity six to seven times per week.

\section{High Blood Pressure, High Cholesterol And Overweight/Obese}

Significantly more single mothers reported high blood pressure $(p=0.004)$ and high cholesterol $(\mathrm{p}=0.017)$ when compared to partnered mothers. Single mothers were nearly three times $(\mathrm{OR}=2.66)$ more likely to experience high blood pressure and two times $(\mathrm{OR}=2.22)$ more likely to have high cholesterol. The majority of single and partnered mothers indicated that a health care professional did not inform them they had high cholesterol $(n=47,72.3 \% ; n=174,85.3 \%$ respectively) or high blood pressure $(n=60$, $77.9 \% ; n=216,90.4 \%$ respectively) (Table 4 ). However, a higher percentage of single mothers $(n=17,22.1 \%$ versus $n=23,9.6 \%$ partnered mothers $)$ were advised they had high blood pressure.

Significant differences were not determined among normal, overweight, and obese BMI categories $(\mathrm{p}=0.288)$ (Table 5$)$. However, significantly more single mothers had a BMI $>25 \mathrm{~kg} / \mathrm{m}^{2}(p=0.01)$. Single mothers $(n=53,72.6 \%)$ were significantly more overweight/obese when compared to partnered mothers $(n=126,55.5 \%)$. 
Table 2. Moderate physical activity of single and partnered mothers from the 2006 Health Survey of Adults and Children in Bermuda.

\begin{tabular}{|c|c|c|c|c|c|c|}
\hline & & \multicolumn{2}{|c|}{ SINGLE MOTHERS } & \multicolumn{2}{|c|}{ PARTNERED MOTHERS } & \multirow[t]{2}{*}{$P$} \\
\hline & & $\mathrm{N}=77$ & $\%$ & $\mathrm{~N}=241$ & $\%$ & \\
\hline \multirow{3}{*}{$\begin{array}{l}\text { Moderate physical activity } \\
\text { (times per week) }\end{array}$} & Less than three & 17 & 22.1 & 76 & 31.5 & \multirow{3}{*}{0.402} \\
\hline & Three to five & 42 & 54.5 & 91 & 37.8 & \\
\hline & Six to seven & 18 & 23.4 & 74 & 30.7 & \\
\hline
\end{tabular}

${ }^{1}$ Moderate Physical Activity: causes small increases in breathing or heart rate, such as brisk walking, bicycling, vacuuming, or gardening. 
Table 3. Vigorous physical activity of single and partnered mothers from the 2006 Health Survey of Adults and Children in Bermuda.

\begin{tabular}{|c|c|c|c|c|c|c|}
\hline & & \multicolumn{2}{|c|}{ SINGLE MOTHERS } & \multicolumn{2}{|c|}{ PARTNERED MOTHERS } & \multirow[t]{2}{*}{$P$} \\
\hline & & $\mathrm{N}=77$ & $\%$ & $\mathrm{~N}=241$ & $\%$ & \\
\hline \multirow{3}{*}{$\begin{array}{l}\text { Vigorous physical activity } \\
\text { (times per week) }\end{array}$} & Less than three & 59 & 76.6 & 165 & 68.5 & \multirow{3}{*}{0.117} \\
\hline & Three to five & 14 & 18.2 & 68 & 28.2 & \\
\hline & Six to seven & 4 & 5.2 & 8 & 3.3 & \\
\hline
\end{tabular}

${ }^{1}$ Vigorous Physical Activity: causes large increases in breathing or heart rate, such as running, aerobics or heavy yard work. 
Table 4. High blood pressure and high cholesterol awareness in single and partnered mothers based on the 2006 Health Survey of Adults and Children in Bermuda.

\begin{tabular}{|c|c|c|c|c|c|c|c|c|}
\hline & & \multicolumn{2}{|c|}{ SINGLE MOTHERS } & \multicolumn{2}{|c|}{ PARTNERED MOTHERS } & \multirow[t]{2}{*}{ ODDS RATIO } & \multirow[t]{2}{*}{$95 \% \mathrm{CI}$} & \multirow[t]{2}{*}{$P$} \\
\hline & & $\mathrm{N}=77$ & $\%$ & $\mathrm{~N}=239$ & $\%$ & & & \\
\hline \multirow{3}{*}{ High blood pressure $^{1}$} & Yes & 17 & 22.1 & 23 & 9.6 & \multirow{2}{*}{2.66} & \multirow{2}{*}{$1.34-5.30$} & \multirow{2}{*}{0.004} \\
\hline & No & 60 & 77.9 & 216 & 90.4 & & & \\
\hline & & $\mathrm{N}=65$ & $\%$ & $\mathrm{~N}=204$ & $\%$ & & & \\
\hline \multirow{2}{*}{ High cholesterol $^{2}$} & Yes & 18 & 27.7 & 30 & 14.7 & \multirow{2}{*}{2.22} & \multirow{2}{*}{$1.14-4.33$} & \multirow{2}{*}{0.017} \\
\hline & No & 47 & 72.3 & 174 & 85.3 & & & \\
\hline
\end{tabular}

${ }^{1}$ High blood pressure: Doctor, nurse, or other health-professional has ever reported to individual they have high blood pressure.

${ }^{2}$ High cholesterol: Doctor, nurse, or other health-professional ever reported to individual they have high cholesterol. 
Table 5. Body mass index (BMI) of single and partnered mothers calculated from self-reported height and weight of the 2006 Health Survey of Adults and Children in Bermuda.

\begin{tabular}{|c|c|c|c|c|c|c|}
\hline & & \multicolumn{2}{|c|}{ SINGLE MOTHERS } & \multicolumn{2}{|c|}{ PARTNERED MOTHERS } & \multirow{2}{*}{$P$} \\
\hline & & $\mathrm{N}=73$ & $\%$ & $\mathrm{~N}=227$ & $\%$ & \\
\hline \multirow{4}{*}{ Body Mass Index (BMI) } & Normal Weight ${ }^{1}$ & 20 & 27.4 & 101 & 44.5 & \multirow{3}{*}{0.288} \\
\hline & Overweight $^{2}$ & 34 & 46.6 & 69 & 30.4 & \\
\hline & Obese $^{3}$ & 19 & 26.0 & 57 & 25.1 & \\
\hline & Overweight $^{2}$ and Obese ${ }^{3}$ & 53 & 72.6 & 126 & 55.5 & 0.010 \\
\hline
\end{tabular}

${ }^{1}$ Normal Weight: BMI value of $18.5-24.9 \mathrm{~kg} / \mathrm{m}^{2}$

${ }^{2}$ Overweight: BMI value of $25-29.9 \mathrm{~kg} / \mathrm{m}^{2}$

${ }^{3}$ Obese: BMI value of $>30 \mathrm{~kg} / \mathrm{m}^{2}$

World Health Organization. Global Database on Body Mass Index. BMI Classification. 2009. Available at: http://aps.who.int 


\section{CHAPTER V}

\section{DISCUSSION}

Presently a paucity of data is available that examines the relationship between partner status and CVD risk factors $(13,14)$. The population of mothers living in Bermuda who responded to the 2006 Health Survey of Adults and Children in Bermuda, demonstrated that single mothers are associated with more CVD risk factors when compared to partnered mothers.

\section{DEMOGRAPHIC FACTORS}

A significant difference was not evident between the ages of the single and partnered mothers. Consistent with results previously established in the U.S., a higher percentage of single mothers reported their race as Black, were less educated, and earned less income annually when compared to partnered mothers (14). In addition, similar results were found for education and income of single mothers at risk for CVD in Canada $(13,14)$. The demographics of single mothers at risk for CVD may be similar throughout Bermuda, the U.S., and Canada as they are all developed nations experiencing an increase in chronic diseases and the risk factors associated with them $(13,14,25)$. As a result, it is possible that the CVD demographic risk factors most evident in single mothers are consistent throughout these countries.

Race, education, and income are all important CVD risk factors for women (12, 13, 48, 49). As these single mothers are women (an established high risk population for CVD), Black, less educated, and have low annual incomes they are essentially at an increased risk for CVD. Risk factors of CVD, specifically prevalence of hypertension and overweight, are significantly different between various racial groups $(50,51)$. Blacks 
have been identified as a high-risk population for having hypertension and being overweight when compared to Whites $(50,51)$. This study revealed further racial disparities between mothers living in Bermuda where most single mothers are Black and most partnered mothers are White. Consequently, these racial differences may have an impact on CVD risk between single and partnered mothers in Bermuda.

Education is a significant component of a woman's, and potentially a mother's CVD risk profile (12). In addition, a low education level (i.e. secondary level education or lower) is a strong predictor of CVD risk in women (12). The fact that single mothers within this study were more likely to have completed secondary level education or lower, may be a predictor of CVD risk for this particular sample.

Single mothers in Bermuda reported having lower annual household incomes when compared to partnered mothers. Despite the differences in cost of living, single mothers in the United States, Canada, and Bermuda are within the lowest income brackets $(13,14)$. Single mothers rely on one income or federal assistance whereas partnered parent families may have two incomes or one high income supporting the household. In addition, socioeconomic status has been identified as an independent significant risk factor for CVD $(12,13,48,49)$. Thus, single mothers are ultimately at a financial disadvantage when compared to partnered mothers. McIntyre and colleagues found when low-income lone mothers $(n=24)$ had inadequate funds they compromised their own food intake to provide for their children (52). Consequently, a lower socioeconomic status impacts not only the mother but the family and ultimately the children (52). Thurston and colleagues identified an inverse association between total family income and incidence of coronary heart disease in both men and women (12). 
Thus, single mothers in Bermuda are associated with lower incomes when compared to partnered mothers which may be influencing their CVD risk profile.

\section{DIETARY FACTORS}

The Bermuda Heart Foundation and the Nutrition Services, Government of Bermuda both recognize nutrition as one of the most important modifiable risk factors of CVD and as such nutrition is an important factor that must be considered when evaluating an individual's CVD risk profile $(46,53)$. The Nutrition Services, Government of Bermuda recommends a total of two to four servings of fruits per day and three to five servings of vegetables per day for an average adult (53). These recommendations, if followed, promote a healthy lifestyle that will support a reduced risk for CVD (53). Women's dietary intake, specifically fruits and vegetables, has been studied extensively in relation to $\operatorname{CVD}(8,54,55)$. In addition, daily breakfast consumption is associated with weight maintenance $(56,57)$. As overweight and obesity are significant risk factors of CVD, breakfast consumption may be an indicator of weight status and CVD risk $(2,5,37,47)$. The Well Bermuda, National Health Promotion Strategy recommends consuming fast-foods less than once per week (25). Thus, if these recommendations are followed they promote a heart healthy dietary lifestyle $(25,58)$.

Furthermore, parents' dietary intake has been found to be indicative of their children's intake $(59,60)$. Thus the dietary habits of mothers, living in Bermuda, may be an important measure of their children's and their family's intake.

\section{$\underline{\text { FRUIT AND VEGETABLE INTAKE }}$}

The majority of all mothers, both single and partnered, in this study consume only one to two servings of fruits and vegetables per day. This low intake of fruits and 
vegetables is associated with an increased risk for $\operatorname{CVD}(8,54,55)$. Both higher education and higher income levels are associated with purchasing more fruits and vegetables (55). Single mothers tended to be less educated and have lower annual incomes which may account for a lower vegetable consumption compared to partnered mothers. In addition, knowledge of relationships between diet and chronic disease are essential for promoting increased intake of fruits and vegetables $(8,54,55)$. In the United Kingdom, awareness of fruit and vegetable recommendations as well as knowledge of the association between fruit and vegetable intake and chronic disease has been found to be minimal (61). It is possible that mothers in Bermuda are unfamiliar with the protective benefits of increased fruit and vegetable intake in relation to lowering the risks for CVD. Furthermore, they may be unaware of strategies to incorporate fruits and vegetables into their diets at the least possible cost.

Mothers who participated in the 2006 Health Survey of Adults and Children in Bermuda were not provided accurate definitions for a serving size of fruits or vegetables. Instead, respondents were asked how many servings of fruit they usually eat, not including fruit juice. Interviewers defined one fruit serving as "a portion of fruit at breakfast" (42). Similarly, a vegetable serving was explained as "a serving of vegetables at both lunch and dinner would be two servings" (42). This is inconsistent with the national definitions set forth by the Bermuda Nutrition Services, Government of Bermuda which specifies a serving is representative of $1 / 2$ cup fruit while a serving of vegetables is equivalent to one cup of leafy greens (44). Lack of an accurate and consistent definition of a serving size for the participants may have led to discrepancies between individual perceptions of fruit and/or vegetable serving size and actual consumption. The 
administration of the survey could be altered to improve the accuracy of the dietary information to be collected. By administering mailed surveys or face-to-face interviews, food frequency questionnaires (with photos of serving sizes) or other dietary recall methodologies (i.e. 24-hour recall) could be utilized to establish regular dietary intake and to eliminate discrepancies between actual and perceived serving sizes.

\section{BREAKFAST CONSUMPTION}

Even though the majority of mothers, single and partnered, in this study were consuming breakfast five to seven times per week, single mothers were more likely to omit breakfast when compared to partnered mothers. Although not documented as a CVD risk factor, breakfast had the potential to be a secondary indicator of CVD risk due to its association with weight gain $(45,56,57)$. Purslow and colleagues conducted an analysis of a population-based cohort study from Norfolk, United Kingdom ( $\mathrm{n}=6764)$. The researchers elucidated that increased percentage of daily energy consumed at breakfast is associated with lower weight gain. Furthermore, it is well documented that

weight gain, overweight, and obesity are all related to increased CVD risk $(2,62)$.

Perhaps, regular consumption of breakfast may be utilized as a potential measure of weight gain and a secondary indicator of CVD risk.

\section{FAST-FOOD CONSUMPTION}

Most single and partnered mothers consumed fast-foods one to two times per week. The Well Bermuda, National Health Promotion Strategy recommends consumption of fast-foods less than once per week to promote a healthy lifestyle (25). Thus, these mothers are not meeting national recommendations. Fast-foods are currently deemed unhealthy due to their known association with having trans-fatty acids, saturated 
fats, cholesterol, sodium, and low levels of fiber, in addition to large portion sizes (58, 63). In addition, fast food consumption has been associated with lower intakes of vegetables and higher intakes of fat (64). Consequently, fast-foods have been identified as promoting weight gain, high blood pressure, and high cholesterol which are all risk factors for CVD $(58,63)$.

\section{Physical ACTIVITy}

The majority of mothers in this study were more likely to engage in moderate physical activity for at least three times per week with vigorous activity less than three times per week. Slightly more partnered mothers, however, were meeting moderate and vigorous physical activity recommendations when compared to single mothers, although the differences were not significant. According to the 2002 Update of American Heart Association Guidelines for Primary Prevention of Cardiovascular Disease and Stroke, it is recommended that adults engage in at least thirty minutes of moderate intensity activity on most (i.e. six to seven) days of the week (47). Added benefits are ensued by engaging in vigorous physical activity for $20-40$ minutes on $3-5$ days per week (47). The American Heart Association physical activity recommendations were utilized for this study because the Bermuda Heart Foundation (the leader in heart health advocacy in Bermuda) refers to AHA recommendations (46). Regular physical activity is an important lifestyle risk factor of CVD as exercise has been proven to protect against CVD (4, 65-67). Consequently single and partnered mothers were not meeting the minimum requirements for both moderate and vigorous physical activity.

These results are consistent with a Canadian study utilizing the National Population Health Survey 1998-1999 where physical activity did not differ significantly 
between single and partnered mothers (13). Conversely, results from the National Health and Nutrition Examination Survey III indicated a significant difference between physical activity of single and partnered mothers (14). This study further reveals evident cultural differences of physical activity in mothers. Physical inactivity of single mothers in Bermuda did not differ significantly as was evident in Canada. Although results are conflicting between Bermuda, Canada, and the U.S., it does seem apparent that physical inactivity of both single and partnered mothers is associated with a greater risk for CVD.

\section{High Blood Pressure, High Cholesterol, and Overweight/Obese}

The current study revealed that more single mothers reported having high blood pressure, high cholesterol, and being overweight when compared to partnered mothers. High blood pressure, high cholesterol, and overweight/obesity are significant risk factors for CVD $(2,3,9,47,54,68,69)$. As high blood pressure is a multi-factorial condition, it is difficult to identify as to whether motherhood status is the major contributing factor to onset in this sample. Black women have higher prevalence of high blood pressure when compared to other ethnicities $(14,70)$. As such, race may have impacted the results where the majority of single mothers in this sample were Black women. High cholesterol is also a significant clinical CVD risk factor for these mothers. This result is consistent with Young et al., who identified more lone mothers with hypercholesterolemia when compared to partnered mothers (14).

Single mothers were more likely to have a BMI greater than $25 \mathrm{~kg} / \mathrm{m}^{2}$ when compared to partnered mothers. Obesity and weight management have been recognized by the American Heart Association as a significant lifestyle risk factor of CVD (47). Obesity was measured by utilization of the body mass index (BMI) which is an indicator 
of overweight status (32). In a cross-sectional study observing the CVD risk factors of women, the researchers concluded that body mass index cannot be used as the sole tool for weight management purposes (2). Thus while BMI was a useful tool in this study there are limitations associated with its utilization due to its sole reflection of height and weight status; this measure does not necessarily take into account the fat mass or lean body mass of the individual. Furthermore, BMI in this study was calculated from selfreported height and weight which may be associated with evident over and underreporting. While these are evident limitations, the Behavioral Risk Factor Surveillance System (BRFSS) has been identified to be highly reliable and valid with regards to BMI (41).

\section{LIMITATIONS}

The analytic sample of this study only included $n=318$ mothers. This is a small sample size that could not be previously determined utilizing sample formulas as it was dependent upon the initial sample obtained from the primary study, 2006 Health Survey of Adults and Children in Bermuda (42). The initial study sample size was established utilizing 1,650 households which represent $6 \%$ of the current household population in Bermuda of approximately 28,000 units (42). The 1,650 households is a statistically representative sample of the household population of Bermuda (42). Within this sample, there were $\mathrm{n}=491$ mothers of which $\mathrm{n}=116$ were single mothers and $\mathrm{n}=375$ were partnered mothers. After removing those mothers who did not meet the inclusion criteria (single or partnered mother living with their children) there were only a total of $\mathrm{n}=318$ all mothers, $\mathrm{n}=77$ single mothers and $\mathrm{n}=241$ partnered mothers. As a result, the analytic sample was reduced due to mothers meeting the inclusion criteria. 
As this was a secondary data analysis, there are evident limitations associated with this study design. The questions and perspectives of the primary study limited the secondary study (71). The primary study sought to understand the health status of adults and children living in Bermuda. Conversely, this secondary data analysis investigated one component of health status, which was heart health. Thus the broad focus of the primary study prevented further in-depth analysis of cardiovascular health and risk factors in mothers. In addition, the secondary study is bound by the time associated with the primary study which was conducted in 2006.

Due to the study design, one cannot generalize the findings to the entire population (i.e. mothers of Bermuda). As the ratio of single mothers to partnered mothers in Bermuda was not attainable for the purposes of this study, the results cannot be generalized to the population of single and/or partnered mothers living in Bermuda. In addition, when conducting secondary data analyses it is recommended using a large sample as this will increase the validity and reliability of the secondary data analyses (72). However, due to the small size of Bermuda (population of approximately 65,000 ) the sample utilized in this secondary data analysis still provided meaningful results.

\section{LIMITATIONS TO QUESTIONNAIRE}

In addition to the study design, the questionnaire of the primary study was also a limitation for this secondary data analysis. This study was limited primarily by the questions posed within the telephone survey and questionnaire. The dietary intake questions (i.e. fruit intake, vegetable intake, breakfast consumption, and fast-food consumption) could have been more precise thus providing a more valid measure of general consumption for these mothers. With regards to fruit and vegetable intake, no 
distinction was made between frozen, dried, fresh, canned or sweetened fruits. In addition, as this was a self-reported telephone survey there may have been discrepancies in over- or under-reporting intake (73). Self-reporting and lack of accurate definitions of servings may be a reason as to why only vegetable intake was significantly different between the single and partnered mothers. Despite the possible limitation of over- or under-reporting, studies have identified the Behavioral Risk Factor Surveillance Survey, which was utilized to develop the 2006 National Health Survey of Adults and Children in Bermuda, to be a valid and reliable tool for measuring fruit and vegetable intake, height, weight, body mass index, blood pressure screening, and demographics (41).

The mothers of this study were not questioned on the length of time of their motherhood. Thus, it is impossible to determine if the lifestyle and CVD risk factors preceded the motherhood or were a result of partner status. Marital status may also have changed throughout the individual's life and as a result it is impossible to identify if partner status was a precursor or successor to the evident CVD risks. Thus future studies should account for marital status changes where possible to obtain a more precise understanding of the relationship between CVD risk factors and motherhood.

In order to further improve upon this study, one could include the more pertinent risk factors of CVD (i.e. smoking). However, due to the dietary focus of this study, these factors were not included. In addition, while examining the data sample there were very few mothers who were currently and/or previously smoking thus this CVD risk factor was omitted from the study. It is also important to note that the analyses did not separate the effects of race, education, income, and age. Thus, by addressing all CVD risk factors 
one could create a more comprehensive assessment of the CVD risk profile of these mothers.

\section{RECOMMENDATIONS}

Based on the findings of the current study, the following recommendations are offered:

1. Nutrition education programs need to be developed, implemented and frequently evaluated for single mothers, perhaps through churches, worksites and government agencies.

2. A Health and Nutrition Survey is warranted every 10 years. Since Bermuda is experiencing an epidemiologic transition where the prevalence of diet-sensitive chronic conditions such as cardiovascular diseases, cancer, diabetes, obesity and overweight is increasing, it is important to identify the dietary excesses and deficiencies of Bermudians.

3. The Health and Nutrition Survey of Bermuda must accurately assess all food categories (i.e. fruit and vegetable intake) by providing accurate and measurable definitions for serving sizes. This will enable study participants the ability to understand the basics of portion control and provide meaningful results for future studies.

DIETARY RECOMMENDATIONS

1. Future health promotion programs need to help mothers to use strategies such as: seasonal fruit and dried fruit as snacks thus modeling appropriate intake for their children and families. 
2. To improve vegetable intake, in Bermudian mothers, health promotion programs need to assist women by promoting: seasonal vegetables and easy preparation methods.

3. To increase breakfast consumption among Bermudian mothers, nutrition education programs must promote: inexpensive, quick, and healthy breakfast options in addition to the importance of eating breakfast regularly for mothers and their families.

4. Future nutrition education programs in Bermuda need to:

a. Encourage fast food restaurants to offer low-fat options;

b. Implement cooking classes utilizing inexpensive food items;

c. Encourage Bermudians to order smaller portion sizes; and

d. Provide mothers with inexpensive cooking classes that promote quick and healthy alternatives to fast food meals.

\section{WEIGHT MANAGEMENT RECOMMENDATIONS}

1. Health promotion and nutrition education programs can focus their efforts on:

a. Portion sizes;

b. Importance of regular breakfast consumption for weight maintenance;

c. Choosing healthy options while eating out;

d. Informing mothers of physical activity recommendations; and

e. Promoting family and community-based prevention programs.

2. Health and Nutrition surveys may incorporate other measures of obesity (i.e. waist circumference) in addition to BMI which can provide a more comprehensive understanding of obesity in mothers living in Bermuda. 


\section{CLINICAL CVD RISK FACTOR RECOMMENDATIONS}

1. Nutrition education programs need to focus on awareness and prevention techniques relating to high blood pressure and high cholesterol that are tailored to the ethnicity of the demographic being served.

2. The Bermuda Heart Foundation and the Bermuda Nutrition Services could provide:

a. Heart healthy recipes that are inexpensive and quick to prepare;

b. Grocery shopping tips and tours for mothers and their families; and

c. Further education addressing the relationship between high blood pressure and high cholesterol on CVD risk.

\section{CONCLUSION}

Single mothers are a high-risk and growing population associated with more CVD risk factors when compared to partnered mothers. In the United States, from 1980 to 2007 , the percentage of live births to single mothers has increased from $18 \%$ to $40 \%$ and between 1980 and 2006 the United Kingdom experienced an increase of $12 \%$ to 44\% and Canada from $13 \%$ to $30 \%$ (74). As a result, there is an evident social shift in family demographics worldwide where single mothers are increasing.

Single mothers in this study tend to be Black, less educated, earn less annually, overweight/obese, eat fewer vegetables, omit breakfast more, and have high blood pressure and high cholesterol when compared to partnered mothers. This suggests that this population may benefit from nutrition education initiatives that are tailored to their demographic. By modifying their dietary habits, the mothers can improve their CVD risk profile (75-76). Improvements in dietary habits can improve the health of mothers and 
ultimately their family and children $(47,60,62)$. Prior studies have identified mothers as the "gatekeepers" and nutrient providers of the home and consequently they have a significant impact on the health status of their family members (20). The current dietary habits of mothers, which may increase risk for CVD incidence, can have an impact on the individual and the family unit. These relationships identify significant public health nutrition issues that can be addressed through nutrition education and community initiatives. In addition, weight loss initiatives are successful at improving food choices and fat habits of overweight mothers and improving dietary habits of their children $(\mathrm{p}<0.01)$ (77). As a result, community-based or family-based primary prevention initiatives would aim to improve the CVD risk profile of mothers and ultimately ensure a healthy environment for their children. It is also important to involve the mothers in the development of primary prevention initiatives, particularly nutrition education programs (78). This will allow for greater adherence and acceptability of programs and will be targeted to the education and financial level of the population.

According to the Well Bermuda, National Health Promotion Strategy of 2006 one of the parenting objectives is to incorporate more parent enrichment opportunities (25). Parent enrichment opportunities can include improving health of the parent and of the family. Well Bermuda also states various heart health objectives such as reducing high blood pressure below $25 \%$ and high cholesterol below $34 \%$ in the Bermudian population (25). By providing nutrition education and implementing CVD awareness programs for mothers, one will ultimately address the Well Bermuda objectives.

Single mothers are an evident high-risk population for developing CVD who require individualized nutrition education and awareness programs. The CVD risk 
profile of single mothers revealed a strong association with their dietary habits. Thus primary prevention through nutrition education can be a useful method of improving the CVD risk profile of these mothers. Furthermore, by addressing cardiovascular and overall health in mothers, one will provide awareness and initiatives for an important and socially influential demographic of women. 


\section{LIST OF REFERENCES}

1. Evans T, Mafubelu D. Women and Health Today's Evidence Tomorrow's Agenda. Geneva, Switzerland: WHO Press; 2009.

2. Ashton WD, Nanchahal K, Wood DA. Body mass index and metabolic risk factors for coronary heart disease in women. Eur Heart J. 2001;22:46-55.

3. Conen D, Ridker PM, Buring JE, Glynn RJ. Risk of cardiovascular events among women with high normal blood pressure or blood pressure progression: prospective cohort study. Brit Med J. 2007;335:432.

4. Gillum RF, Mussolino ME, Ingram DD. Physical activity and stroke incidence in women and men. Am J Epidemiol. 1996;143:860-869.

5. Jousilahti P, Vartiainen E, Tuomilehto J, Puska P. Sex, age, cardiovascular risk factors, and coronary heart disease: a prospective follow-up study of 14786 middle-aged men and women in Finland. Circulation. 1999;99:1165-1172.

6. Kurth T, Moore SC, Gaziano M et al. Healthy lifestyle and the risk of stroke in women. Arch Intern Med. 2006;166:1403-1409.

7. Lerman A, Sopko G. Women and cardiovascular heart disease: clinical implications from the women's ischemia syndrome evaluation (WISE) study. J Am Coll Cardiol. 2006;47:59S-62S.

8. Liu S, Manson JE, Lee I et al. Fruit and vegetable intake and risk of cardiovascular disease: the Women's Health Study. Am J Clin Nutr. 2000;72:9228.

9. Roeters van Lennep JE, Westerveld HT, Erkelens W, van der Wall EE. Risk factors for coronary heart disease: implications of gender. Cardiovasc Res. 2002;53:538-549.

10. Stampfer MJ, Hu FB, Manson JE, Rimm EB, Willett WC. Primary prevention of coronary heart disease in women through diet and lifestyle. $N$ Engl J Med. 2000;343:16-22.

11. Sundaram AA, Ayala C, Greenlund KJ, Keenan NL. Differences in the prevalence of self-reported risk factors for coronary heart disease among American women by race/ethnicity and age. Am J Prev Med. 2005;29:25-30. 
12. Thurston RC, Kubzansky LD, Kawachi I, Berkman LF. Is the association between socioeconomic position and coronary heart disease stronger in women than in men? Am J Epidemiol. 2005;162:57-65.

13. Young LE, James AD, Cunningham SL. Lone motherhood and risk for cardiovascular disease - the national population health survey (NPHS), 1998-99. C J Public Health. 2004;95:329-335.

14. Young LE, Cunningham SL, Buist DSM. Lone mothers are at higher risk for cardiovascular disease compared with partnered mothers. Data from the national health and nutrition examination survey II (NHANES III). Health Care Women In. 2005;26:604-621.

15. MacKinnon-Lewis C, Rabiner D, Starnes R. Predicting boys' social acceptance and aggression: the role of mother-child interactions and boys' beliefs about peers. Dev Psychol. 1999;35:632-639.

16. Birney MH, Hardie TL, Crowley EM. Association of parental smoking behaviors and absences in school-age children: implications for the nurse practitioner. $J \mathrm{Am}$ Acad Nurse Prac. 2006;18:221-227.

17. Aronowitz T, Rennells RE, Todd E. Heterosocial behaviors in early adolescent African American girls: the role of mother-daughter relationships. J Fam Nurs. 2005;11:122-139.

18. Social and Demographic Division Department of Statistics. Characteristics of Bermuda's Families. Hamilton, Bermuda; 2006.

19. Roeters van Lennep JE, Westerveld HT, Erkelens W, van der Wall EE. Risk factors for coronary heart disease: implications of gender. Cardiovasc Res. 2002;53:538-549.

20. Oliveria SA, Ellison RC, Moore LL, Gillman MW, Garrahie EJ, Singer MR. Parent-child relationships in nutrient intake: the Framingham Children's Study. Am J Clin Nutr. 1992;56:593-598.

21. Farr W. Influence of Marriage On the Mortality of the French People. London: Savill and Edwards; 1859.

22. Reeves J, Kendrick D, Denman S, Roberts H. Lone mothers: their health and lifestyle. Health Educ J. 1994;53:291-299. 
23. Burstrom B, Diderichsen F, Shouls S, Whitehead M. Lone mothers in Sweden: trends in health and socioeconomic circumstances, 1979-1995. J Epidemiol Community Health. 1999;53:750-756.

24. Higgins JW, Young L, Cunningham S, Naylor PJ. Out of the mainstream: lowincome, lone mothers' life experiences and perspectives on heart health. Health Promot Pract. 2006;7:221-233.

25. Attride-Stirling J. Well Bermuda: A National Health Promotion Strategy. Government of Bermuda: Department of Health. 2006.

26. Wild RA, Taylor EL, Knehans A, Cleaver V. Matriarchal model for cardiovascular prevention. Obstet Gynecol Surv. 1994;49:147-152.

27. Beardsworth $\mathrm{AD}$ et al. Women, men and food: the significance of gender for nutritional attitudes and choices. British Food J. 2002;104:470-491.

28. Jilcott SB, Laraia BA, Evenson KR, Ammerman A. Perceptions of the Community Food Environment and Related Influences on Food Choice Among Midlife Women Residing in Rural and Urban Areas: A Qualitative Analysis. Women Health. 2009;49:164-180.

29. Gillman MW et al. Family Dinner and Diet Quality Among Older Children and Adolescents. Arch Fam Med. 2000;9:235-240.

30. Sallis JF, Patterson TL, McKenzie TL, Nader PR. Family Variables and Physical Activity in Preschool Children. J Dev Behav Pediatr. 1988;9:57-61.

31. Mosca L, Jones WK, King KB, Ouyang P, Redberg RF, Hill MN. Awareness, perception, and knowledge of heart disease risk and prevention among women in the United States. Arch Fam Med. 2000;9:506-515.

32. World Health Organization. Global Database on Body Mass Index. Available at: http://apps.who.int. Updated February 21, 2010. Accessed February 21, 2010.

33. Tjepkema M. Adult obesity in Canada: Measured height and weight. Statistics Canada. Available at: http://www.statcan.gc.ca. Updated November 16, 2008. Accessed November 11, 2009.

34. Centers for Disease Control and Prevention. Overweight and Obesity. U.S. Obesity Trends. Available at: http://www.cdc.gov. Updated November 20, 2009. Accessed February 20, 2010. 
35. Pan L, Galuska DA, Sherry B et al. Differences in prevalence of obesity among Black, White, and Hispanic adults - United States, 2006-2008. Morbidity and Mortality Weekly Report. 2009;58:740-744.

36. Tjepkema M. Nutrition Findings from the Canadian Community Health Survey Adult obesity in Canada: Measured height and weight. Ottawa, Canada: 2008.

37. Lichtenstein AH, Appel AJ, Brands M et al. Diet and lifestyle recommendations revision 2006: a scientific statement from the American heart association nutrition committee. Circulation. 2006;114:82-96.

38. American Heart Association. International Cardiovascular Disease Statistics. Available at: http://www.americanheart.org. Updated 2009. Accessed November 11, 2009.

39. Behavioral Risk Factor Surveillance System. Turning Information Into Health. 2009. Available at: http://www.cdc.gov/brfss. Accessed October 22, 2009.

40. Stein AD, Lederman RI, Shea S. The Behavioral Risk Factor Surveillance System Questionnaire: Its Reliability in a Statewide Sample. Am J Public Health. 1993;83:1768-1772.

41. Nelson DE, Holtzman D, Bolen J, Stanwyck CA, Mack KA. Reliability and validity of measure from the Behavioral Risk Factor Surveillance System (BRFSS). Soz Praventivmed. 2001;46:S3-42.

42. Attride-Stirling J, Boney C, DeRoza D, Trott D. Department of Health. Health Survey of Adults and Children in Bermuda 2006. Government of Bermuda. 2007.

43. United Kingdom Statutory Instrument. SI 1968 No. 182. The Constitution of Bermuda. Bermuda Constitution Order 1968.

44. Bermuda's Guide to Daily Food Choices. Nutrition Services. Ministry of Health, Social Services \& Housing. Available at: http://www.gov.bm. Accessed November 12, 2009.

45. Purslow LR, Sandhu MS, Forouhi N et al. Energy intake at breakfast and weight change: prospective study of 6,764 middle-aged men and women. $\mathrm{Am} J$ Epidemiol. 2008;167:188-192.

46. Bermuda Heart Foundation. Available at: http://www.mybermudaheart.bm. Accessed August 12, 2009. 
47. Pearson TA, Blair SN, Daniels SR et al. AHA guidelines for primary prevention of cardiovascular disease and stroke: 2002 update: consensus panel guide to comprehensive risk reduction for adult patients without coronary or other atherosclerotic vascular diseases. Circulation. 2002;106:388-391.

48. Barcelo MA, Saez M, de Tuero GC. Individual socioeconomic factors conditioning cardiovascular disease risk. Am J Hypertens. 2009;22:1085-1095.

49. Kaplan GA, Keil JE. Socioeconomic factors and cardiovascular disease: a review of the literature. Circulation. 1993;88:1973-1998.

50. Burt VL, Whelton P, Roccella EJ et al. Prevalence of hypertension in the US adult population. Results from the third national health and nutrition examination survey, 1988-1991. Hypertension. 1995; 25: 305-313.

51. McGruder HF, Malarcher AM, Antoine TL, Greenlund KJ, Croft JB. Racial and ethnic disparities in cardiovascular risk factors among stroke survivors: United States 1999 to 2001. Stroke. 2004;35:1557-1561.

52. McIntyre L, Officer S, Robinson LM. Feeling poor: the felt experience lowincome lone mothers. Affilia. 2003;18:316-331.

53. Food and Nutrition Services. Department of Health Government of Bermuda. Available at: http://www.gov.bm. Accessed November 29, 2009.

54. Djousse L, Arnett DK, Coon H, Province MA, Moore LL, Ellison RC. Fruit and vegetable consumption and LDL cholesterol: the national heart, lung, and blood institute family heart study. Am J Clin Nutr. 2004;79:213-217.

55. Elfhag K, Tholin S, Rasmussen F. Consumption of fruit, vegetables, sweets and soft drinks are associated with psychological dimensions of eating behavior in parents and their 12-year-old children. Public Health Nutr. 2008;11:914-923.

56. Schlundt DG, Hill JO, Sbrocco T, Pope-Cordle J, Sharp T. The role of breakfast in the treatment of obesity: a randomized clinical trial. Am J Clin Nutr. 1992;55:645-651.

57. Song WO, Chun K, Obayashi S, Cho S, Chung CE. Is consumption of breakfast associated with body mass index in US adults? J Am Diet Assoc. 2005;105:13731382.

58. Pereira MA, Kartashov AI, Ebbeling CB, Slattery ML, Jacobs DR, Ludwig DS. Fast-food habits, weight gain, and insulin resistance (the CARDIA study): 15-year prospective analysis. Lancet. 2005;365:36-42. 
59. Johnson SL, Birch LL. Parents' and children's adiposity and eating style. Pedatr. 1994;94:653-661.

60. Bourdeaudhuij ID. Perceived family members' influence on introducing healthy food into the family. Health Educ Res. 1997;12:77-90.

61. Baker AH, Wardle J. Increasing Fruit and vegetable intake among adults attending colorectal cancer screening: the efficacy of a brief tailored intervention. Cancer Epidem Biomar. 2002;11:203-206.

62. Morrison JA, Payne G, Barton BA, Khoury PR, Crawford P. Mother-daughter correlations of obesity and cardiovascular disease risk factors in black and white households: the NHLBI growth and health study. Am J Public Health. 1994;84:1761-1767.

63. Isganaitis E, Lustig RH. Fast food, central nervous system insulin resistance, and obesity. Arterioscler Thromb Vasc Biol. 2005;25:2451-2462.

64. Satia JA, Galanko JA, Siega-Riz AM. Eating at fast-food restaurants is associated with dietary intake, demographic, psychosocial and behavioural factors among African Americans in North Carolina. Public Health Nutr. 2004;7:1089-1096.

65. Hu FB, Stampfer MJ, Colditz GA et al. Physical activity and risk of stroke in women. J Amer Med Assoc. 2000;283:2961-2967.

66. Leitzmann MF, Park Y, Blair A et al. Physical activity recommendations and decreased risk of mortality. Arch Intern Med. 2007;167:2453-2460.

67. Alevizos A, Lentzas J, Kokkoris S, Mariolis A, Korantzopoulos P. Physical activity and stroke risk. Int J Clin Pract. 2005;59:922-930.

68. Nordestgaard BG, Benn M, Schnohr P. Nonfasting triglycerides and risk of myocardial infarction, ischemic heart disease, and death in men and women. $J$ Amer Med Assoc. 2007;298:299-308.

69. Ford ES, Mokdad AH, Giles WH, Mensah GA. Serum total cholesterol concentrations and awareness, treatment, and control of hypercholesterolemia among US adults: finding from the national health and nutrition examination survey, 1999 to 2000. Circulation. 2003;107:2185-2189.

70. Lloyd-Jones DM. Ethnic Variation in hypertension among premenopausal and perimenopausal women: study of women's health across the nation. Hypertension. 2005;46:689-695. 
71. Rew L, Koniak-Griffin D, Lewis MA, Miles M, O’Sullivan A. Secondary data analysis: new perspective for adolescent research. Nurs Outlook. 200;48:223-229.

72. Huston $\mathrm{P}$, Naylor CD. Health services research: reporting on studies using secondary data sources. Can Med Assoc J. 1996;155:1697-1709.

73. Schoeller DA. Limitations in the assessment of dietary energy intake by selfreport. Metabolis. 1995;44:18-22.

74. Centers for Disease Control and Prevention. National Center for Health Statistics Office of Communication. Increase in Unmarried Childbearing Also Seen in Other Countries. 2009. Available at: http://www.cdc.gov. Accessed November 28, 2009.

75. Richardson G, van Woerden HC, Morgan L et al. Healthy hearts - a communitybased primary prevention programme to reduce coronary heart disease. $B M C$ Cardiovasc Disord. 2008;8:18-25.

76. Stampfer MJ, Hu FB, Manson JE, Rimm EB, Willett WC. Primary Prevention of coronary heart disease in women through diet and lifestyle. $N$ Engl J Med. 2000;343:16-22.

77. Klohe-Lehman DM, Freeland-Graves J, Clarke KK et al. Low-income, overweight and obese mothers as agents of change to improve food choices, fat habits, and physical activity in their 1-to-3-year-old children. J Am Coll Nutr. 2007;26:196-208.

78. Rysdale L. Evaluation of a nutrition education component nested in the NutriSTEPTM project. Can J Diet Prac Res. 2008;69:38-42. 